Article

\title{
Comparison of Catalytic Activity of ZIF-8 and Zr/ZIF-8 for Greener Synthesis of Chloromethyl Ethylene Carbonate by $\mathrm{CO}_{2}$ Utilization
}

\author{
Bisi Olaniyan and Basudeb Saha * \\ School of Engineering, London South Bank University, 103 Borough Road, London SE1 0AA, UK; \\ olaniyab@lsbu.ac.uk \\ * Correspondence: b.saha@lsbu.ac.uk; Tel.: +44-(0)20-7815-7190; Fax: +44-(0)20-7815-7699
}

Received: 26 November 2019; Accepted: 15 January 2020; Published: 21 January 2020

\begin{abstract}
The catalytic activity of both ZIF-8 and Zr/ZIF-8 has been investigated for the synthesis of chloromethyl ethylene carbonate (CMEC) using carbon dioxide $\left(\mathrm{CO}_{2}\right)$ and epichlorohydrin $(\mathrm{ECH})$ under solvent-free conditions. Published results from literature have highlighted the weak thermal, chemical, and mechanical stability of ZIF-8 catalyst, which has limited its large-scale industrial applications. The synthesis of novel $\mathrm{Zr} / \mathrm{ZIF}-8$ catalyst for cycloaddition reaction of $\mathrm{ECH}$ and $\mathrm{CO}_{2}$ to produce $\mathrm{CMEC}$ has provided a remarkable reinforcement to this weak functionality, which is a significant contribution to knowledge in the field of green and sustainable engineering. The enhancement in the catalytic activity of $\mathrm{Zr}$ in $\mathrm{Zr} / \mathrm{ZIF}-8$ can be attributed to the acidity/basicity characteristics of the catalyst. The comparison of the catalytic performance of the two catalysts has been drawn based on the effect of different reaction conditions such as temperature, $\mathrm{CO}_{2}$ pressure, catalyst loading, reaction time, stirring speed, and catalyst reusability studies. Zr/ZIF-8 has been assessed as a suitable heterogeneous catalyst outperforming the catalytic activities of ZIF-8 catalyst with respect to conversion of ECH, selectivity and yield of CMEC. At optimum conditions, the experimental results for direct synthesis of CMEC agree well with similar literature on $\mathrm{Zr} / \mathrm{MOF}$ catalytic performance, where the conversion of $\mathrm{ECH}$, selectivity and the yield of CMEC are $93 \%, 86 \%$, and $76 \%$, respectively.
\end{abstract}

Keywords: $\mathrm{ECH}$; epichlorohydrin; $\mathrm{CMEC}$; chloromethyl ethylene carbonate; $\mathrm{CO}_{2}$; carbon dioxide; MOF; metal organic framework; ZIF-8; zeolitic imidazolate framework; Zr/ZIF-8; zirconium/zeolitic imidazolate framework

\section{Introduction}

The effective transformation and utilization of anthropogenic carbon dioxide $\left(\mathrm{CO}_{2}\right)$ is a subject of political and environmental debates in recent years, which have been actively pursued by the academia and energy industries in order to promote a sustainable environment [1]. The current level and accumulation of $\mathrm{CO}_{2}$ in the atmosphere is high and requires urgent attention [2]. However, regardless of environmental regulations and discharge limits placed on greenhouse gases emitted into the atmosphere, $\mathrm{CO}_{2}$ is believed to be environmentally benign, abundant, nontoxic, non-flammable, and a readily available $\mathrm{C} 1$ source for the synthesis of organic carbonate [3]. Therefore, the synthesis of cyclic organic carbonates via the cycloaddition of $\mathrm{CO}_{2}$ and epoxides is one of the most promising reaction schemes because of its $100 \%$ atom efficiency [4]. Cyclic organic carbonates such as chloromethyl ethylene carbonate (CMEC), propylene carbonate (PC), styrene carbonate (SC), and ethylene carbonate (EC) are widely used as polar aprotic solvents, electrolytes for lithium-ion batteries, automobile, cosmetic, fuel additives materials, alkylating and carbonylating reagents, and fine chemicals for pharmaceuticals $[5,6]$. 
In the past two decades, several attempts have been made to develop greener and sustainable catalytic systems for chemical fixation of $\mathrm{CO}_{2}$. This includes conventional solid catalysts such as zeolites, salen $\mathrm{Cr}$ (III) complexes, metal oxides, quaternary ammonium salts, polymer-supported catalysts, ionic liquids (ILs), etc. However, these attempts have failed to yield satisfactory results as most of these catalysts require high temperature and/or pressure (usually around $453 \mathrm{~K}$ and pressure higher than $8 \mathrm{~atm}$ ), further separation and purification steps, and low product yield [7]. This is uneconomical from a commercial point of view and hence, the research has been directed to employ a novel catalyst that provides solutions to all these shortfalls i.e., metal organic framework (MOF). Although, microporous materials such as zeolites, crystalline aluminosilicate, activated carbon, etc. have been known for their high surface area and high porosity, however, their applications have been limited especially in the field of heterogeneous catalysis due to difficulty in pore modification [7].

Metal organic framework (MOF) catalysts are identified as multidimensional porous polymetric crystalline organic-inorganic hybrid materials with exceptional characteristics including an ultrahigh specific surface area, enormous pore spaces, and ordered crystalline structure [8]. MOFs have emerged as a suitable candidate for the synthesis of organic carbonates from $\mathrm{CO}_{2}$ and epoxide due to their unique heterogeneity and reusability requirements [9]. MOF-based catalysts often display higher catalytic activity than their corresponding homogenous catalysts as evidenced in many catalytic reactions such as ring opening, addition reactions, oxidation reactions, hydrogenation and isomerization [10]. Zeolitic imidazolate frameworks, (ZIFs), is one of the subclasses of MOFs with a similar structure to zeolites. It has attractive structural properties and intrinsically lower density. Many experiments involving ZIF-8 have shown great applications in multidisciplinary fields such as catalysis, drug deliveries, purification and gas storage [11].

Recently, the stability of MOFs for large-scale industrial applications has been questioned in many published papers [11-15]. This is due to their weak thermal, chemical, and mechanical stability due to the structure of inorganic bricks and the nature of the chemical bonds they form with the linker [15]. In order to improve this weak thermal functionality and gain in-depth knowledge of their catalytic activities, Cavka et al. [16] was the first group to synthesize Zr-based MOFs designated as zirconium 1,4-dicarboxybenzene, UiO-66 for photocatalysis [17]. The test conducted by the group found that the increased stability of the $\mathrm{Zr}$-based MOFs is owing to the $\mathrm{Zr}$-O bonds formed between the cluster and carboxylate ligands [18]. Several other groups have thereafter explored this opportunity, which has seen the increased application of Zr-based MOFs in many research activities. Demir et al. [19] utilized $\mathrm{UiO}$ (University of Oslo) type zirconium metal-organic frameworks in a solvent-free coupling reaction of carbon dioxide $\left(\mathrm{CO}_{2}\right)$ and epichlorohydrin $(\mathrm{ECH})$ for the synthesis of epichlorohydrin carbonate (ECHC). The results of their experiments have increased the use of zirconium-based (Zr-based) MOFs for the catalytic synthesis of organic carbonates from $\mathrm{CO}_{2}$ and epoxides.

From our experiments, the synthesis of $\mathrm{Zr}$-doped MOF (Zr/ZIF-8) for the cycloaddition reaction of $\mathrm{CO}_{2}$ and $\mathrm{ECH}$ in the synthesis of chloromethyl ethylene carbonate (CMEC) has demonstrated reasonable thermal stability under relatively mild reaction conditions without using any solvent or co-catalyst. Although, the synthesis of several Zr-based MOFs have been reported in recent times (albeit in early stages), only a few were employed for catalytic studies even more rarely for the synthesis of organic carbonates from $\mathrm{CO}_{2}$ and epoxides. Zr-based MOFs have exhibited increased structural tailorability as a result of the organic linkers in the catalyst frameworks [19].

Zirconium-based MOFs have demonstrated proof-of-concept applications in several areas such as toxic analyte, catalysis, gas storage, vivo drug delivery, and bio-sensing [20]. In this paper, a novel $\mathrm{Zr} / \mathrm{ZIF}-8$ has been successfully synthesized using the conventional solvothermal method. The prepared catalyst has been assessed as an innovative greener and sustainable heterogeneous catalyst for the direct synthesis of $\mathrm{CMEC}$ from $\mathrm{CO}_{2}$ and $\mathrm{ECH}$. The effect of various reaction parameters has been investigated and critically analyzed. These include the effect of reaction time, catalyst loading, temperature, $\mathrm{CO}_{2}$ pressure, and stirring speed. Catalyst reusability studies of $\mathrm{Zr} / \mathrm{ZIF}-8$ was also investigated to establish its stability and reusability for the synthesis of CMEC. 


\section{Experimental Methods}

\subsection{Chemicals and Materials}

Acetone (99\%), chloromethyl ethylene carbonate (99\%), epichlorohydrin (purity; 99\%), zinc nitrate hexahydrate $\left(\mathrm{Zn}\left(\mathrm{NO}_{3}\right)_{2} \cdot 6 \mathrm{H}_{2} \mathrm{O}\right.$ (purity; $99 \%$ ), dimethylformamide (purity; 99\%), and zirconium (IV) oxynitrate hydrate $\left(\mathrm{ZrO}\left(\mathrm{NO}_{3}\right)_{2} \cdot 6 \mathrm{H}_{2} \mathrm{O}, 99.99 \%\right)$ were purchased from Sigma-Aldrich Co. LLC, Dorset, UK. Methanol (99\%) and n-pentane 99.8\%) were both procured from Fisher Scientific UK Ltd, Loughborough, UK. ZIF-8 catalyst was purchased from Sigma-Aldrich Co. LLC under the trademark of Basolite Z1200. All chemicals and catalysts were used without further purification or pre-treatment.

\subsection{Catalysts Preparation}

Preparation of ZIF-8 and zirconium-doped ZIF-8 (Zr/ZIF-8) were synthesized according to a method, which was previously described elsewhere [20,21]. Briefly, $8 \mathrm{mmol}$ of zinc nitrate hexahydrate $\left(\mathrm{Zn}\left(\mathrm{NO}_{3}\right)_{2} \cdot 6 \mathrm{H}_{2} \mathrm{O} 99.99 \%\right)$ and zirconium (IV) oxynitrate hydrate $\left(\mathrm{ZrO}\left(\mathrm{NO}_{3}\right)_{2} \cdot 6 \mathrm{H}_{2} \mathrm{O}, 99.99 \%\right)$ solutions in a stoichiometric ratio of $\mathrm{Zn}: \mathrm{Zr}=10: 0$ and $\mathrm{Zr}: \mathrm{Zn}=9: 1$ (to synthesis ZIF-8 and Zr/ZIF-8 respectively) were dissolved in $6.2 \mathrm{mmol}$ of methanol. A separate solution of $14.2 \mathrm{mmol}$ of 2-methylimidazole and $600 \mathrm{mml}$ of methanol was prepared in another flask, which was added by dropwise addition to the $\mathrm{Zr}-\mathrm{Zn}$-based solution. The mixture conducted in an ambient temperature under nitrogen flow was vigorously stirred for $6 \mathrm{~h}$. The Zr-doped ZIF- 8 crystals were collected and separated by centrifugation at $300 \mathrm{rpm}$ for $30 \mathrm{~min}$. The solution was washed thoroughly with methanol three times and then dried at room temperature conditions. The crystals were left to dry overnight at $373 \mathrm{~K}$. The greyish-white powders of Zr-ZIF-8 samples were further washed with DMF for $24 \mathrm{~h}$ in order to remove any excess of an unreacted organic linker. The solution was then heated at a temperature of $373 \mathrm{~K}$ in order to activate it. The samples were allowed to cool to room temperature naturally before being capped in a vial and refrigerated, ready for use in catalytic reactions. The obtained samples were identified with a stoichiometric ratio of $\mathrm{Zr}: \mathrm{Zn}=10: 0$ and $\mathrm{Zr}: \mathrm{Zn}=1: 9$ for $\mathrm{ZIF}-8$ and $\mathrm{Zr} / \mathrm{ZIF}-8$ respectively.

\subsection{Experimental Procedure for the Synthesis of Chloromethyl Ethylene Carbonate (CMEC)}

In a typical cycloaddition reaction, a $25 \mathrm{~mL}$ stainless steel high-pressure reactor was initially charged with a specific amount of $\mathrm{Zr} / \mathrm{ZIF}-8$ catalyst and the limiting reactant, epichlorohydrin. A desired temperature was set on the reactor's panel controller; the reactor was then sealed and stirred continuously at a known stirring speed. At the desired temperature, a specific amount of liquid $\mathrm{CO}_{2}$ was charged through a supercritical fluid (SCF) pump into the reactor. The reaction was left for the desired reaction time. After the reaction was completed, the reactor was cooled down to room temperature and the mixture was collected and filtered. The catalyst was separated, washed with acetone, and dried in a vacuum oven. A known amount of methanol (used as internal standard) was added to the product and analyzed using a gas chromatograph (GC). The effect of different reaction parameters was investigated. These include catalyst loading, stirring speed, $\mathrm{CO}_{2}$ pressure, temperature, and reaction time. Reusability studies of both catalysts were also carried out in order to investigate the stability of the catalysts for the synthesis of chloromethyl ethylene carbonate.

\subsection{Method of Analysis}

A specific quantity of internal standard, methanol added to a known sample of the product was analyzed using a gas chromatography (GC) (Model: Shimadzu GC-2014). The stationary phase was a capillary column with dimensions (30 m length, $320 \mu \mathrm{m}$ inner diameter, and $0.25 \mu \mathrm{m}$ film thickness). Oxygen (99.9\%) and hydrogen (99.9\%) were used as ignition gases. The carrier gas used for the mobile phase was a high purity helium $(99.9 \%)$ with a flow rate maintained at $1 \mathrm{~mL} \mathrm{~min}^{-1}$. A temperature program was developed for the system where both the injector port and detector temperatures were kept isothermally at $523 \mathrm{~K}$. The other selected program includes split ratio of 50:1 and injection volume of $0.5 \mu \mathrm{L}$. The column temperature was initially maintained at $323 \mathrm{~K}$ for $5 \mathrm{~min}$, then followed by a 
temperature ramp at a flow rate of $50 \mathrm{~K} \mathrm{~min}^{-1}$ to a temperature of $523 \mathrm{~K}$ with a $12 \mathrm{~min}$ run for each subsequent samples. The chromatogram shows that ECH peak at $\sim 3.5 \mathrm{~min}$, methanol at $\sim 3.8 \mathrm{~min}$, CMEC at $11 \mathrm{~min}$.

\subsection{Proposed Reaction Mechanism}

The proposed reaction mechanism involves two steps:

- The ring-opening of epoxides by a catalyst;

- Incorporation of carbon dioxide into the opening to form the cyclic carbonate.

The coupling reaction of $\mathrm{CO}_{2}$ with epoxides can be initiated by activating either the epoxide or $\mathrm{CO}_{2}$ or both at the same time [22]. This reaction, using a suitable heterogeneous catalyst, produces desired organic carbonates along with other side products. Figure 1 shows reaction pathways 1,2, and 3 with corresponding products being chloromethyl ethylene carbonate, 3-chloropropane 1,2-diol, and 2,5-bis (chloromethyl)-1,4-dioxane respectively. The epoxide is activated when the oxygen atom interacts with the Lewis acid, this is then followed by a nucleophilic attack that provokes the opening of the epoxide ring [23] as shown in Figure 2. The activation of $\mathrm{CO}_{2}$ can occur both through a nucleophilic attack with the oxygen atom as a nucleophile or an electrophilic attack with the carbon atom as an electrophile [24]. Figure 2 shows a proposed reaction mechanism for the synthesis of CMEC, where $\mathrm{R}$ is an alkyl group, $A$ is a metal atom with a Lewis acid site, while $B$ is an oxygen atom with a Lewis basic site. Zr/ZIF- 8 is a dual-functional catalyst, which contains both the acidic and basic sites that are associated with the Lewis acid $\mathrm{Zn}^{2+}$ ions and the basic imidazole groups, respectively. The by-products identified with the coupling reaction of $\mathrm{CO}_{2}$ and $\mathrm{ECH}$ as identified by the GC analysis are 3-chloropropane 1,2-diol and 2,5-bis (chloromethyl)-1,4-dioxane (see Figure 1). Figure 3 shows the schematic representation of the reaction of $\mathrm{CO}_{2}$ and $\mathrm{ECH}$ to produce CMEC.

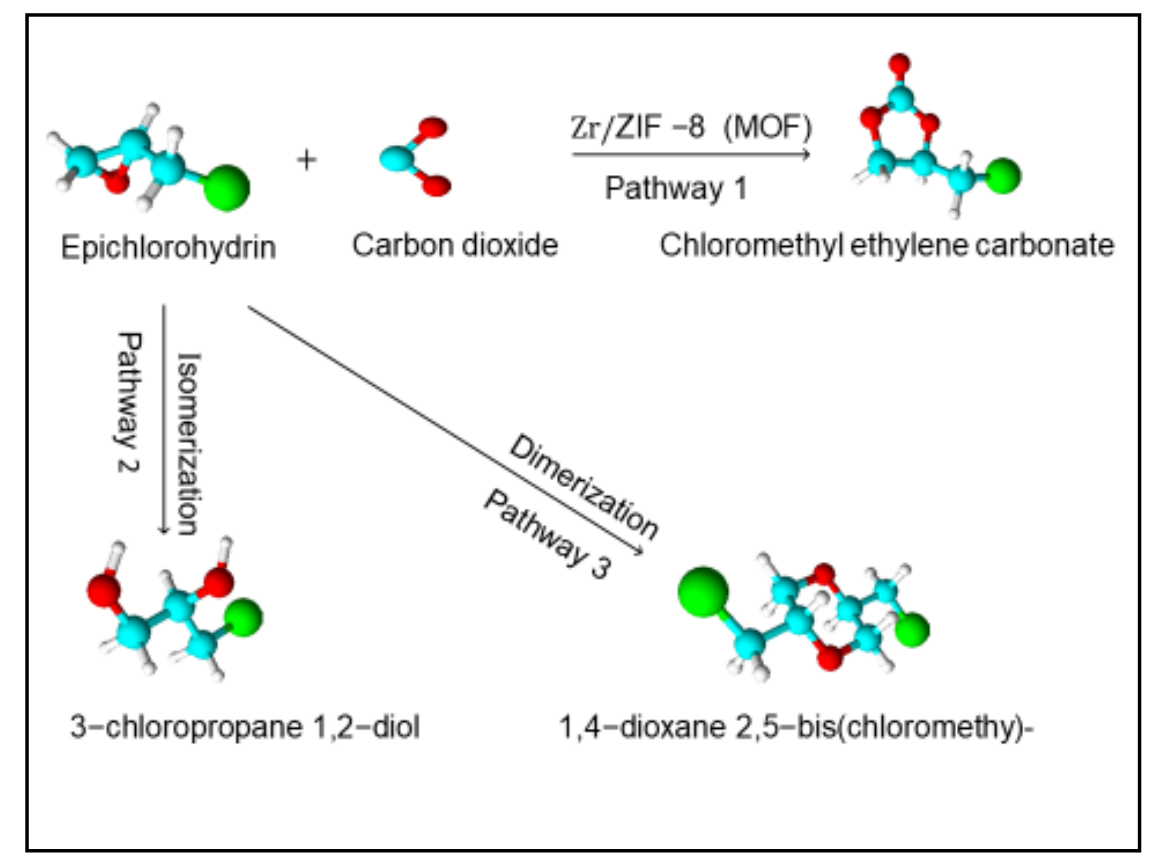

Figure 1. Reaction pathways for cycloaddition reaction of epichlorohydrin $(\mathrm{ECH})$ and carbon dioxide $\left(\mathrm{CO}_{2}\right)$. 


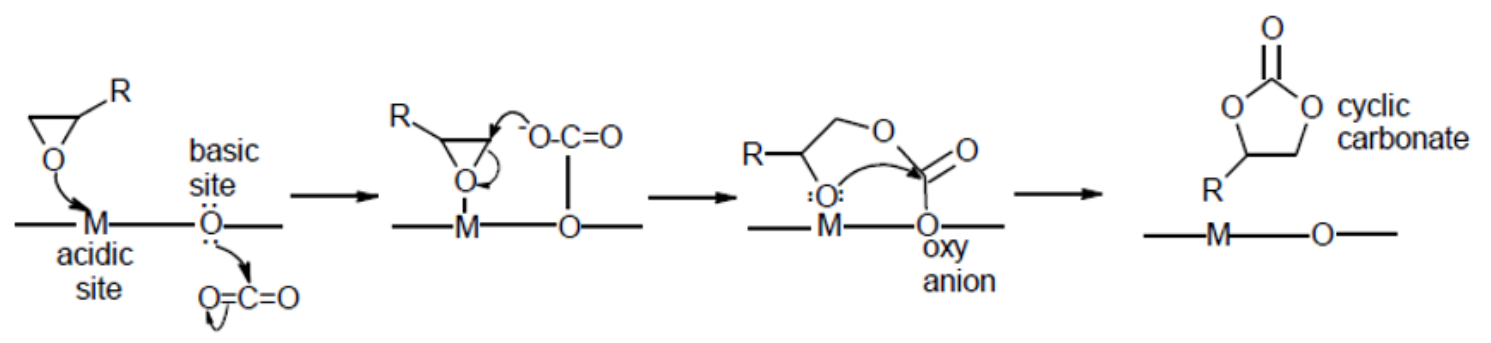

Figure 2. Proposed reaction mechanism for the cycloaddition reaction of $\mathrm{CO}_{2}$ to $\mathrm{ECH}$ over an acid-base pairs. $\mathbf{R}$ is an alkyl group, $\mathbf{M}$ is a metal atom (acidic site), and $\mathbf{O}$ is oxygen atom (basic site).

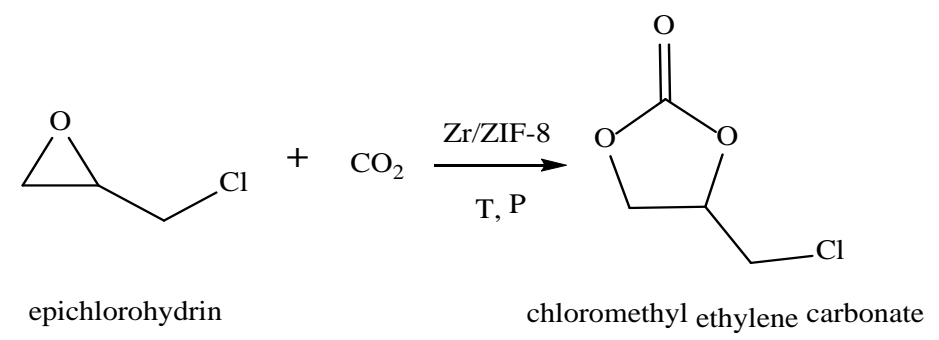

Figure 3. Schematic representation of $\mathrm{ECH}-\mathrm{CO}_{2}$ cycloaddition reaction.

\subsection{Catalyst Characterization}

The powder X-ray diffraction (XRD) patterns of the samples was analyzed at room temperature with a characteristics peaks range of $5<2 \theta<35$ at a scanning rate of $0.5^{\circ} \mathrm{min}^{-1}$. The catalyst was placed on a zero-background silicon sample holder using a Bruker D8 advance X-ray diffractometer in transmission geometry with $\mathrm{CuK} \alpha$ radiation $\left(\lambda=1.5406^{\circ} \mathrm{A}\right)$ at $40 \mathrm{kV}$ and $40 \mathrm{~mA}$. The samples were slightly grinded before measurements were taken so as to prevent preferential orientation of individual crystals during sample analysis.

The Brunauer-Emmett-Teller (BET) surface area of the as-prepared catalyst was analyzed with a Micromeritics Gemini VII analyzer at room temperature (291 K). Prior to BET analysis, the samples were degreased in a turbomolecular pump vacuum at $423 \mathrm{~K}$ for $8 \mathrm{~h}$. The surface area and nitrogen adsorption/desorption isotherm measurements were taken at liquid nitrogen temperature of $77 \mathrm{~K}$ (purge gas supplied by BOC, UK). In order to achieve greater degree of accuracy in the accumulation of the adsorption data, the Micromeritics Gemini analyzer was fitted with pressure transducers to cover the range of $133 \mathrm{~Pa}, 1.33 \mathrm{kPa}$, and $133 \mathrm{kPa}$.

The Fourier transform infrared (FTIR) spectra $\left(4500-600 \mathrm{~cm}^{-1}\right)$ of the samples were obtained using Nicolet Magna-IR 830 spectrometer in KBr disks at room temperature with a resolution of $2 \mathrm{~cm}^{-1}$. The specimen was mixed $\mathrm{KBr}$ in ratio 1:300, the mixture was ground in an agate mortar to a very fine powder. The product was oven dried for $12 \mathrm{~h}$ at $373 \mathrm{~K}, 250 \mathrm{mg}$ of the dry samples were used to make a pallet; the pallet was analyzed, and the spectra were recorded by 32 scans with $4 \mathrm{~cm}^{-1}$.

Particle size morphologies and microstructures of the as-synthesized $\mathrm{Zr} / \mathrm{ZIF}-8$ catalyst was examined using the JEOL JSM-35C instrument operated at voltage $20 \mathrm{kV}$ acceleration. Prior to imaging, the specimen was carbon-coated $(5-10 \mathrm{~nm})$ under a vacuum condition using Emitech K550X sputter coater, this was done to enhance material conductivity. The particle mean size of the specimen were calculated by taking a manual measurement of about 300 crystals in the SEM images using the field emission scanning electron microscope (FE-SEM). FE-SEM spectra produced were used to examine the particle size and morphology.

Transmission electron microscopy (TEM) images of the catalyst were examined using a high resolution TEM (HRTEM). A sample of the specimen was sonicated in ethanol for $15 \mathrm{~min}$ and was then placed by a dropwise onto a carbon film-supported copper grid. The as-prepared sample was allowed to dry at room temperature before inserting into a sample holder. X-ray photoelectron spectroscopy (XPS) of the samples was recorded on the krato axis ultra DLD photoelectron spectrometer, a surface 
science instrument SSx-100 using a monochromatic Al KR X-ray source operating at $144 \mathrm{~W}$. Raman spectroscopy measurements of the specimen were taken at room temperature with the Horiba Jobin Yvon LabRAM spectrometer equipped with an aHeNe laser operating at a wavelength of $633 \mathrm{~nm}\left(\mathrm{E}_{\mathrm{ex}}\right.$ $=1.96 \mathrm{eV}$ ) and Coherent Innova 70 ion laser at a wavelength of $458 \mathrm{~nm}, 488 \mathrm{~nm}$, and $514 \mathrm{~nm}$.

\section{Results and Discussion:}

\section{Catalyst Characterization}

The X-ray diffraction patterns of ZIF-8, Zr/ZIF-8 and recycled Zr/ZIF-8 are shown in Figure 4. The diffraction peaks appeared at small $2 \theta$ angles with eight diffraction peaks at $7.31,10.31,12.71$, $14.71,16.41,18.01,24.61$, and 26.71 which are indexed to the (011), (002), (112), (022), (013), (222), (233), and (134) planes, respectively. The XRD patterns of both Zr/ZIF-8 and recycled Zr/ZIF-8 catalysts are identical as shown in Figure 4, confirming that Zr/ZIF-8 has high crystal stability under the normal reaction conditions. These results are in agreement with simulated patterns reported in other literature [25-28]. The decrease in peak intensity of these diffractions was also observed at $\left(2 \theta=28-35^{\circ}\right)$ indicating the effect of excess doping of Zr into the ZIF-8 framework. The XRD pattern of Zr/ZIF-8 also show a characteristic peak of ZIF-8 with no diffraction peak of zirconium nitrate.

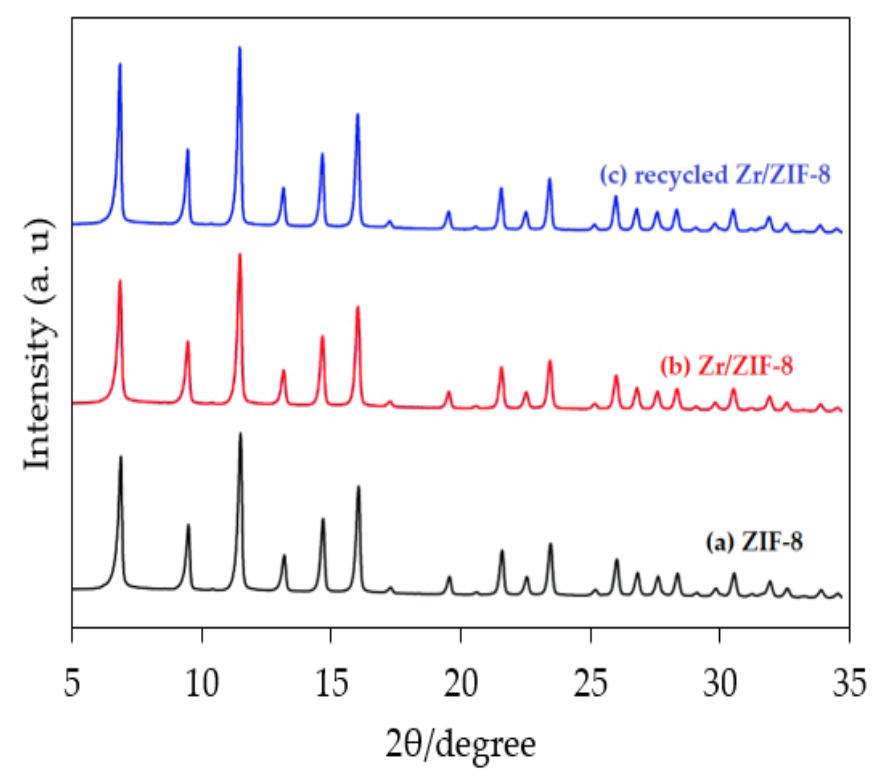

Figure 4. X-ray diffraction (XRD) patterns of (a) ZIF-8, (b) Zr/ZIF-8, and (c) recycled Zr/ZIF-8 catalysts.

Although, the peak intensity of Zr/ZIF-8 may be slightly lower when compared to commercial Basolite Z1200, purchased from Sigma Aldrich. Nevertheless, the experiments of Nordin et al. [29] They establishes that guest molecules (such as zirconium) occupying MOF pore spaces may cause pattern destructive and subsequently, a retarded gas uptake capacity in the MOF. A further and in-depth examination of the XRD patterns of the specimen beyond this study could reveal some surprising details as doping of zirconium into ZIF-8 could enlarge its pore spaces [30], thereby inducing a crystallographic defect in the Zr/ZIF-8 catalyst.

The nitrogen adsorption-desorption isotherms of ZIF-8, Zr/ZIF-8, and the recycled Zr/ZIF-8 catalysts are shown in Figure 5. The samples were measured at liquid temperature of $77 \mathrm{k}$ at $373 \mathrm{~K}$ for $24 \mathrm{~h}$. The three isotherms showed an attribute of a microporous framework with a sharp hysteresis loop of P/P0 between 0.8 and 1.0. However, the pristine ZIF- 8 catalyst demonstrates a typical type-I isotherm behavior [31] while $\mathrm{Zr} / \mathrm{ZIF}-8$ and the recycled $\mathrm{Zr} / \mathrm{ZIF}-8$ catalysts both shows typical type-IV isotherms with a type $\mathrm{H}_{4}$ hysteresis loop in the range of $\mathrm{P} / \mathrm{P0}=0.4-0.8$ indicating the presence of mesopores [32]. Meanwhile, an increase in the volume adsorbed at low relative pressure is consistent with interparticle 
voids, which is indicative of dual macro-mesoporosity of the $\mathrm{Zr} / \mathrm{ZIF}-8$ lattice according to International Union of Pure and Applied Chemistry (IUPAC) classification [33,34].

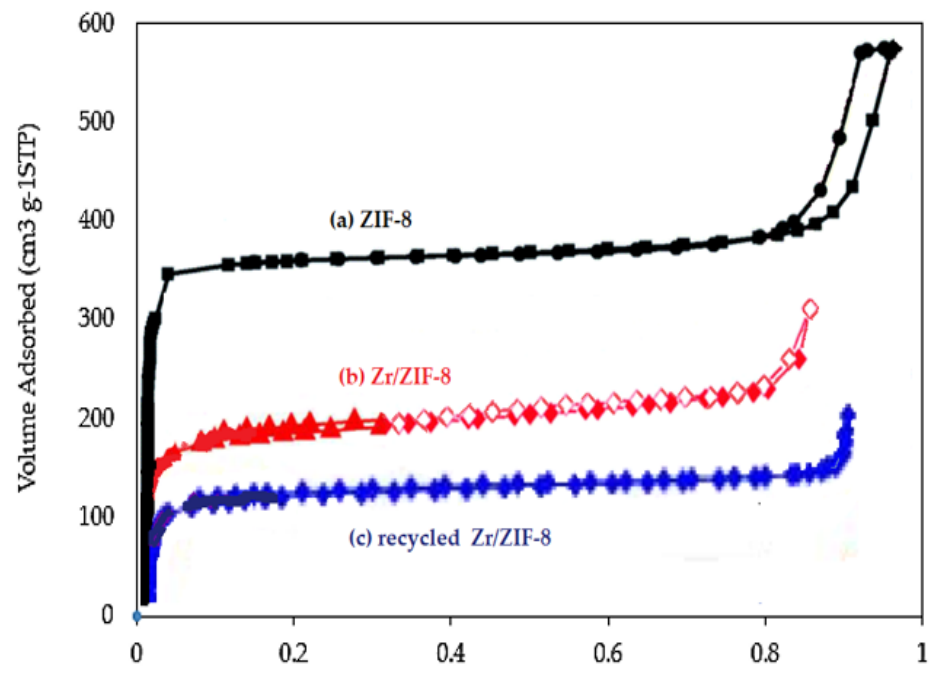

Figure 5. $\mathrm{N}_{2}$ adsorption-desorption isotherms of (a) ZIF-8, (b) Zr/ZIF-8, and (c) recycled Zr/ZIF-8 synthesized with $10 \%$ dopant of Zr.

The specific BET surface area $\left(\mathrm{S}_{\mathrm{BET}}\right)$ of the catalysts has been calculated using the BET equation. The pore size distribution was derived from the nonlinear density functional theory (DFT) model (calculated using computer software). The surface area and micropore volume of $\mathrm{Zr} / \mathrm{ZIF}-8$ was generally lower than ZIF-8 as shown in Table 1. The lower BET surface area and pore volume of Zr/ZIF-8 may be caused by the blockage of the pore cavities of the host molecule as a result of deposition of zirconium particles in the ZIF-8 shell, a phenomenon that has been previously reported by Na et al. [35]. Surprisingly, the total pore volume and the BET specific surface area of recycled Zr/ZIF- 8 catalyst both decreased after the reaction. This observation may be attributed to agglomeration of coke deposits in the pore spaces, resulting in the blockage of some micropores and mesopores. [36].

Table 1. Comparison of Brunauer-Emmett-Teller (BET) surface area analysis, pore-volume, and pore size for ZIF-8 and Zr/ZIF-8 crystals.

\begin{tabular}{ccccc}
\hline Entry & Material & $\begin{array}{c}\mathbf{S}_{(\mathrm{BET})} \\
\left(\mathbf{m}^{\mathbf{2}} \cdot \mathbf{g}^{\mathbf{- 1}} \mathbf{)}\right.\end{array}$ & $\begin{array}{c}\text { Pore Volume } \\
\left(\mathbf{c m}^{\mathbf{3}} \cdot \mathbf{g}^{-\mathbf{1}} \mathbf{)}\right.\end{array}$ & $\begin{array}{c}\text { Pore Size } \\
(\mathbf{n m})\end{array}$ \\
\hline 1 & ZIF-8 & 1700 & 0.664 & 1.30 \\
2 & Zr/ZIF-8 & 1458 & 0.536 & 1.23 \\
3 & Zr/ZIF-8 (recycled) & 1378 & 0.498 & 1.21 \\
\hline
\end{tabular}

These results reflect a good pore size distribution of the samples microporous network $[37,38]$. Although, variation may exist in particles BET surface area and pore volume from one literature to another, this may be attributed to post-synthesis work-up procedures such as further purification processes and activation of MOF samples [39]. The BET surface area as shown in Figure 5 is in agreement with the previous literature [40].

Figure 6 shows the morphologies and microstructures of ZIF-8, fresh and recycled Zr/ZIF-8 catalysts using the scanning electron microscope (SEM) with an average particle size diameter of $100 \mu \mathrm{m}$. Figure 6a shows an evolution of ZIF-8 crystal from cubes with 6 faces (100) to intermediates shapes, and finally to a more stable equilibrium rhombic dodecahedral shape with edges exposing 12 faces (110) [41]. Figure $6 \mathrm{~b}$ (Zr/ZIF-8) revealed very slight morphological alterations to the Figure 6a (ZIF-8) framework. The slight alterations are a genuine indication of a stable $\mathrm{Zr} / \mathrm{ZIF}-8$ catalyst comparing to the report of Pang et al. [41]. Furthermore, the hexagonal shape of the recycled catalyst in 
Figure $6 c$ showed a very small change after the cycloaddition reaction. A close examination of the SEM images of Figure $6 a, b$ shows no significant effect of attrition on the overall particle aggregation between the two structures. The SEM image of recycled Zr/ZIF-8 in Figure $6 \mathrm{c}$ showed rather small isolated monodispersed particles with a well-defined truncated rhombic dodecahedron structure caused by the presence of dopant in the host molecule. Essentially, the SEM images of the samples are consistent with the XRD results and the thermal stability of Zr/ZIF-8 as shown in the catalyst reusability studies. It is worth mentioning that, the increased average crystal size of the recycled Zr/ZIF-8 catalyst in the range of $~ 100-170 \mathrm{~nm}$ (Figure 6c) may be attributed to Ostwald ripening and/or recrystallization effect [42], a phenomenon which explains a possible increase in the average crystal size of the reused catalyst during cycloaddition reaction, especially at a higher temperature (reaction temperature $353 \mathrm{~K}$ ).
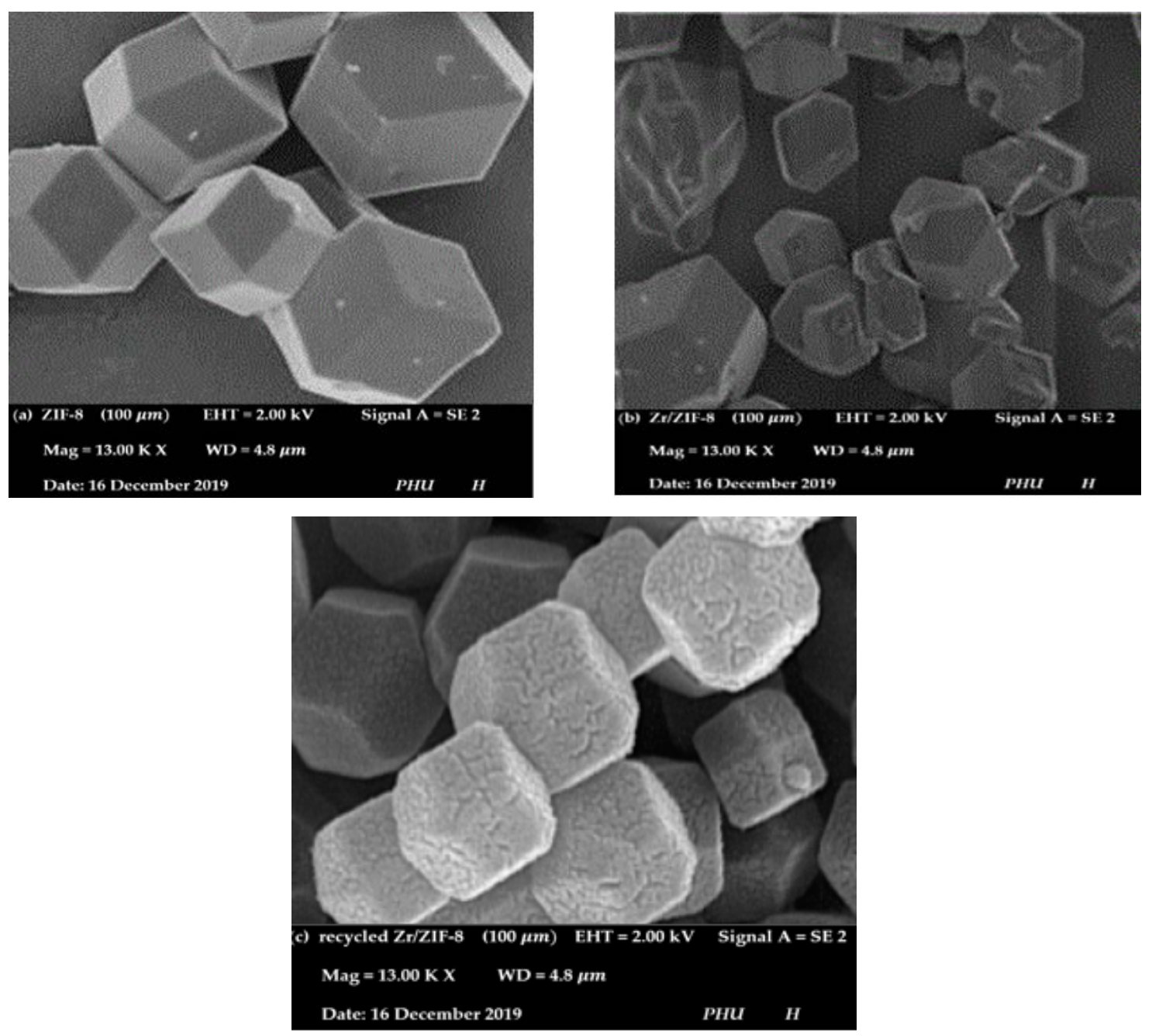

Figure 6. Scanning Electron Microscope (SEM) images of (a) ZIF-8 crystals, (b) Zr/ZIF-8, and (c) recycled $\mathrm{Zr} / \mathrm{ZIF}-8$ crystals synthesized with $10 \%$ dopant of $\mathrm{Zr}$.

Low-magnification TEM images of the samples were carried out in order to examine the structural changes taking place on the surface of the samples. Figure $7 \mathrm{a}, \mathrm{b}$ showed well-shaped high-quality homogenous crystals with a remarkable rhombic dodecahedral shape and average crystal size of about $100 \mu \mathrm{m}$ which conforms to earlier literature [42]. It can be observed from the image in Figure $7 \mathrm{~b}$ that there are no obvious aggregations or changes in particle size and morphology from Figure 7a. The TEM image of the recycled catalyst (Figure 7c) shows that the catalyst crystals were highly stable during the cycloaddition reaction of $\mathrm{CO}_{2}$ and $\mathrm{ECH}$. 

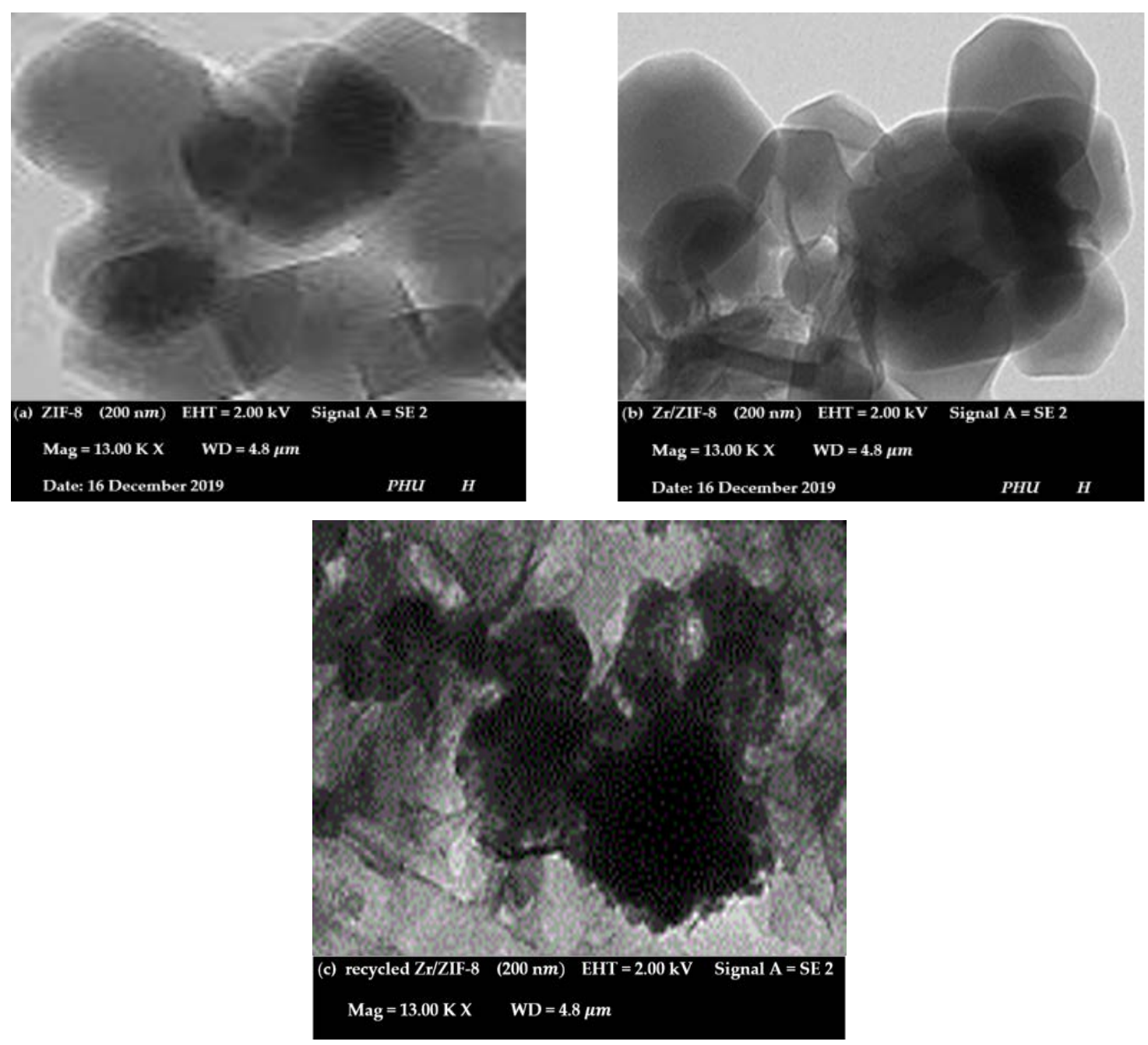

Figure 7. Transmission electron microscopy (TEM) image of (a) pristine ZIF-8 crystals, (b) Zr/ZIF-8, and (c) recycled $\mathrm{Zr} / \mathrm{ZIF}-8$ synthesized with $10 \%$ dopant of $\mathrm{Zr}$.

Figure 8 shows the Fourier-transform infrared spectroscopy (FTIR) spectra of ZIF-8, Zr/ZIF-8, and the recycled $\mathrm{Zr} / \mathrm{ZIF}-8$ with an absorption region of $500-4000 \mathrm{~cm}^{-1}$. The three samples show several bands with no substantial difference in the spectra. For example, a typical adsorption band at $423 \mathrm{~cm}^{-1}$ is attributed to the $\mathrm{Zn}-\mathrm{N}$ bond vibrations indicating that zinc molecules of the imidazole ring are well-knitted during the reaction to nitrogen atoms in 2-methylimidazolate (2-Hmim) linkers to form the ZIF frameworks [43]. The absorption spectra at $2926 \mathrm{~cm}^{-1}$ can be ascribed to the aromatic moieties, while the spectra at $3133 \mathrm{~cm}^{-1}$ can be attributed to the aliphatic imidazole ring due to $\mathrm{C}-\mathrm{H}$ stretching [44]. The missing adsorption spectra in the region of 3400 to $2200 \mathrm{~cm}^{-1}$ is a strong indication of a fully deprotonated imidazole ring during the formation of the ZIF-8 frameworks [44]. The strong sharp peak at $1449 \mathrm{~cm}^{-1}$ can be assigned to the $C-C$ bonding in the benzene ring. The peak at $1579 \mathrm{~cm}^{-1}$ can be attributed to $\mathrm{C}=\mathrm{N}$ vibrations mode [45], while the spectra in the band range between 1100 and $400 \mathrm{~cm}^{-1}$ can be assigned to $\mathrm{C}-\mathrm{N}$ stretching vibrations. The small peaks at 1245 and 1255 can be assigned to $\mathrm{C}-\mathrm{N}$ and $\mathrm{C} \equiv \mathrm{N}$ groups respectively indicating the presence of imidazole molecules in the samples frameworks. The $\mathrm{Zr}-\mathrm{N}$ bonding vibration located between 550 and $620 \mathrm{~cm}^{-1}$ in $\mathrm{Zr} / \mathrm{ZIF}-8$ catalyst [46]. All characteristic peaks of ZIF-8 can be observed both in Zr/ZIF-8 and the recycled $\mathrm{Zr} / \mathrm{ZIF}-8$, indicating a successful combination and interaction between $\mathrm{Zr}$ and ZIF-8. This observation is a strong indication that the frameworks of ZIF-8 have not been affected after the incorporation of Zr. This results in agreement with the report of Giraldo et al. [47] experiments. 


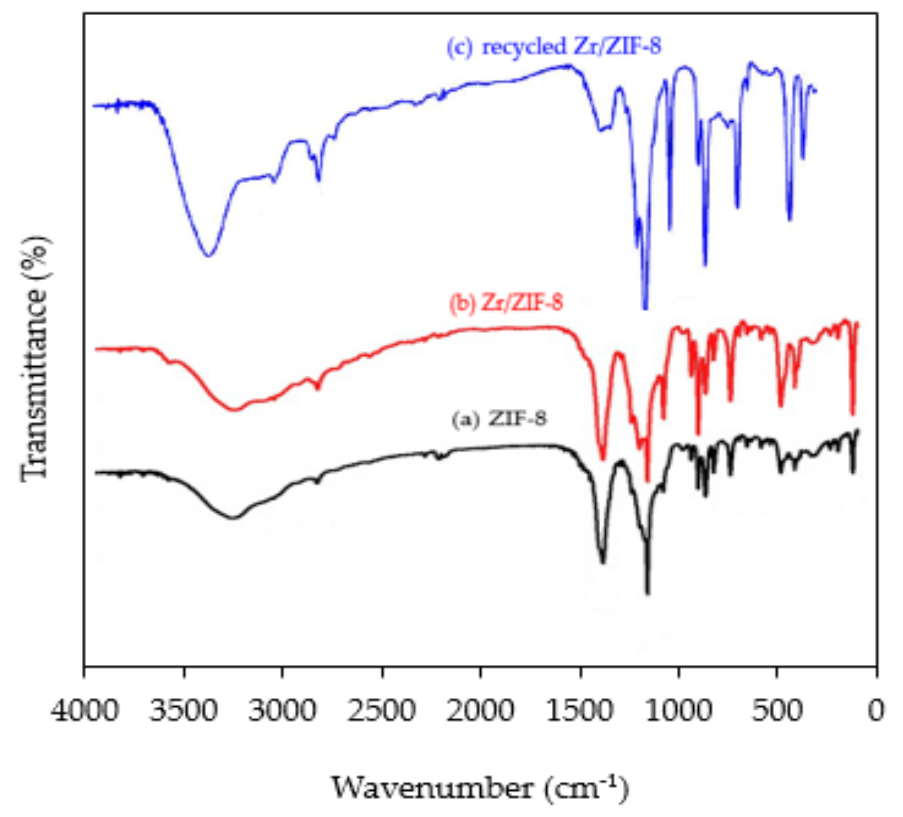

Figure 8. Fourier-transform infrared spectroscopy (FTIR) spectra of (a) ZIF-8, (b) Zr/ZIF-8, and (c) recycled $\mathrm{Zr} / \mathrm{ZIF}-8$ particles.

The X-ray photoelectron spectroscopy (XPS) spectra in Figure 9 clearly shows the chemical state of the element present in pristine ZIF-8 frameworks $(\mathrm{Zn}, \mathrm{C}, \mathrm{N})$ and $\mathrm{O}$, while those elements present in $\mathrm{Zr} / \mathrm{ZIF}-8$ sample include $\mathrm{Zn}, \mathrm{C}, \mathrm{N}, \mathrm{O}$, and $\mathrm{Zr}$ species. Figure 9a exhibits high resolution XPS spectra showing two strong peaks with binding energy of 1044.3 and $1021.1 \mathrm{eV}$ which can be assigned to $\mathrm{Zn} 2 \mathrm{p}^{\frac{1}{2}}$ and $\mathrm{Zn} 2 \mathrm{p}^{3 / 2}$ components, respectively, confirming the presence of $\mathrm{Zn}$ (II) ions attached with nitrogen in the imidazole ring [48]. This result is consistent with the XRD results. With the incorporation of $\mathrm{Zr}$ into ZIF-8, the binding energy of $Z n 2 p^{1 / 2}$ and $2 p^{3 / 2}$ have slightly increased, this could be as a result of the chemical environment of zinc and the interaction between zinc and zirconium. All spectra have been normalized to the magnitude of the $\mathrm{Zn} 2 \mathrm{p}^{3 / 2}$ and $\mathrm{Zn} 2 \mathrm{p}^{1 / 2}$ peaks, so that changes in intensity are relative to the amount of $\mathrm{Zn}$ in the surface region. Similarly, Figure $9 \mathrm{~b}$ shows high-resolution N1s spectra of all samples. The N1s spectra can be deconvoluted into three characteristic peaks found at 399.0 and 399.8 and $398 \mathrm{eV}$ which can be assigned to the pyridinic, pyrrolic, and graphitic, respectively. These can be related to the $\mathrm{N}$ species of the 2-methyl imidazole ring [48]. C1s spectra shows four different characteristic peaks corresponding to $\mathrm{C}-\mathrm{C}$ at $284.1 \mathrm{eV}, \mathrm{C}-\mathrm{N}$ at $285.8 \mathrm{eV}, \mathrm{C}-\mathrm{O}$ at $286.4 \mathrm{eV}$, all assigned to the 2-methyl imidazole ring [48]. The low peak found at $283.4 \mathrm{eV}$ could be as a result of $\mathrm{Zr}$ doping into ZIF-8 frameworks [48]. Figure 9d shows high resolution O1 spectra that has been deconvoluted into two characteristic peaks with binding energy 532.3 and $531.8 \mathrm{eV}$ corresponding to $\mathrm{O}^{2-}$ found in $\mathrm{Zn}-\mathrm{O}$ bonding and carboxylate species, respectively [49]. The relatively low peak intensity of $\mathrm{Zr}-\mathrm{O}$ in $\mathrm{O} 1 \mathrm{~s}, \mathrm{C} 1 \mathrm{~s}$, and N1s is a strong indication that the ZIF-8 frameworks are not affected by the presence of dopant, which perfectly agreed with the result of Mao et al. [50].

Raman spectra of ZIF-8, Zr/ZIF-8 and the recycled Zr/ZIF-8 were observed using a Renishaw Ramascope 1000 (model: 52699). Figure 10 shows that $\mathrm{Zr} / \mathrm{ZIF}-8$ exhibited several Raman spectra at the following peaks $687,892,1149,1186,1462,1568,2931,3114$, and $3131 \mathrm{~cm}^{-1}$ similar to ZIF-8 spectra. The spectra at 1116 and $1484 \mathrm{~cm}^{-1}$ corresponding to bands D and G, respectively, found in the Raman spectrum of ZIF-8, have not been observed in the Zr/ZIF-8 and the recycled Zr/ZIF-8 spectra. This may be as a result of a split of the main bands at 1143 and $1508 \mathrm{~cm}^{-1}$ as previously reported by Biswal et al. [51]. The spectra found at $278 \mathrm{~cm}^{-1}$ may be attributed to $\mathrm{Zn}-\mathrm{N}$ stretching, while the spectra at $683,1143,1456$, and $1508 \mathrm{~cm}^{-1}$ are attributed to imidazole ring puckering, $\mathrm{C} 5-\mathrm{N}$ vibrations, methyl bending, and $\mathrm{C} 4=\mathrm{C} 5$ stretching, respectively, which are similar to the observation of Tanaka et al. [52]. The remaining spectra can be assigned to stretching and bending on the imidazole ring [53]. With 
doping of Zr into the ZIF-8 frameworks, the peaks at 1116 and 1484 disappeared with no significant change in main peaks on spectra [54]. The spectra of three samples shows similar vibration modes, which confirms structural equality in the frameworks.
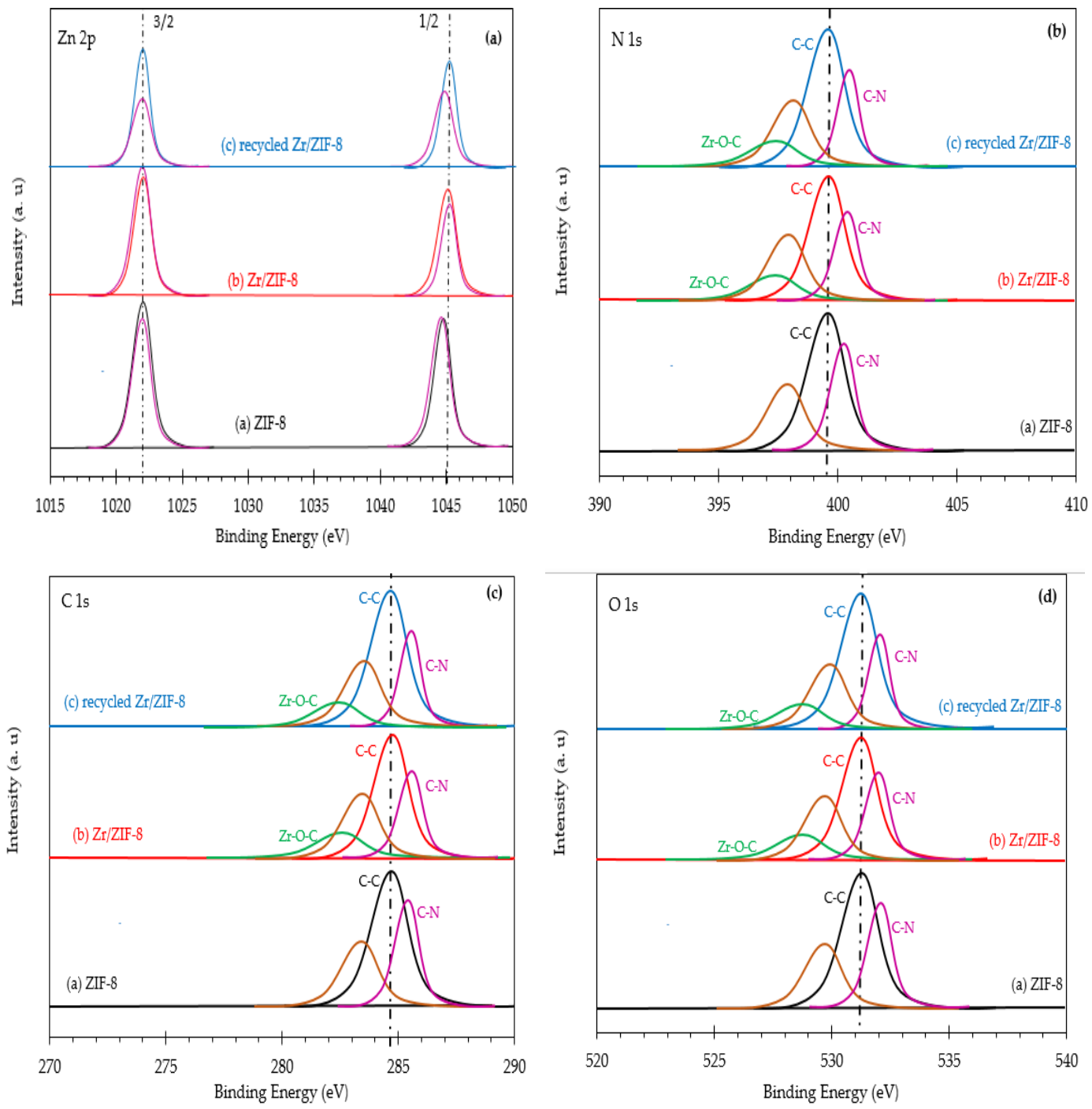

Figure 9. X-ray photoelectron spectroscopy (XPS) spectra showing deconvoluted regions of ZIF-8, $\mathrm{Zr} / \mathrm{ZIF}-8$ catalyst, and recycled Zr/ZIF-8 catalysts. (a) Zn 2p, (b) N 1s, (c) C 1s, (d) O 1s.

There are three distinct phases of weight loss experienced by both samples as indicated in Figure 11. It can be observed from the thermogram that, both catalysts experienced a very small initial weight loss of about $3 \%$ in the region from 298 to $373 \mathrm{~K}$ in the first phase. This can be attributed to loss of water and some guest molecules (e.g., methanol) and possibly some unreacted species trapped in the pore cavities of the framework. As the temperature was further increased through the second phase, $\mathrm{Zr}$ /ZIF-8 experienced a gradual and steady weight loss up to $723 \mathrm{~K}$ and then remained stable thereafter until $973 \mathrm{~K}$. Conversely, ZIF-8 experienced a rapid and significant weight loss of around $54 \%$ up to $823 \mathrm{~K}$, attributing the decomposition of some absorbed organic ligand and the final weight loss phase experienced the collapse of the ZIF-8 structure at high temperature [53]. It is worth noting that materials stability of the ZIF-8 framework can be attributed to the incorporation of zirconium in ZIF-8. A similar observation was reported by Wang et al. [54] in the doping of lanthanum into ZIF-8. After the decomposition, approximately $39 \%$ of the starting weight remained. From this observation, 
it can be concluded that the $\mathrm{Zr} / \mathrm{ZIF}-8$ catalyst frameworks have remained structurally stable and this is consistent with XRD and SEM.

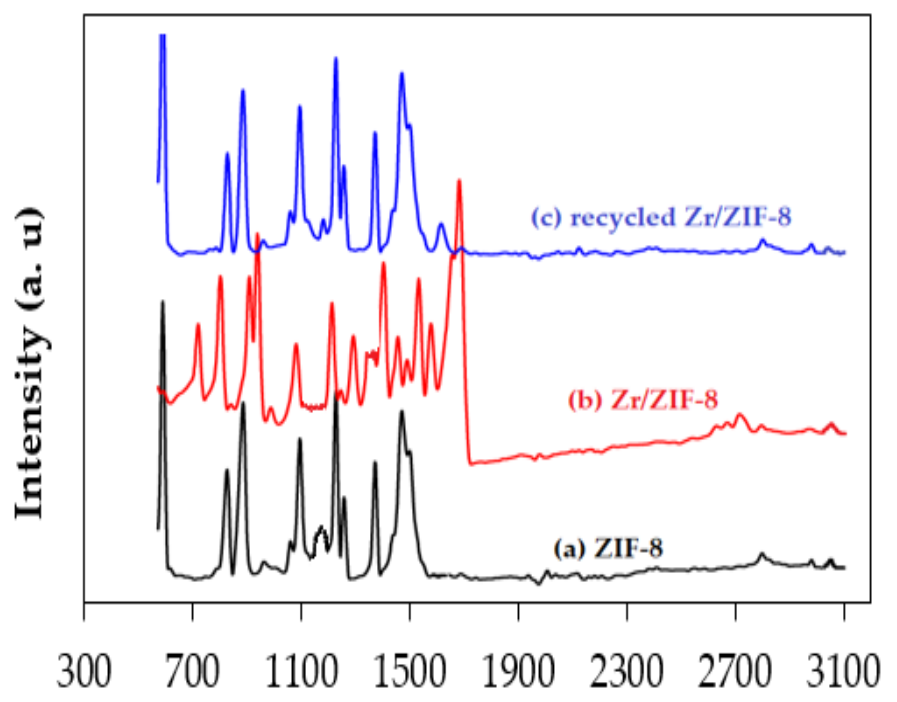

Raman Shift $/ \mathrm{cm}^{-1}$

Figure 10. Raman spectra of the crystal-size (a) ZIF-8, (b) Zr/ZIF-8, and (c) recycled Zr/ZIF-8 samples.

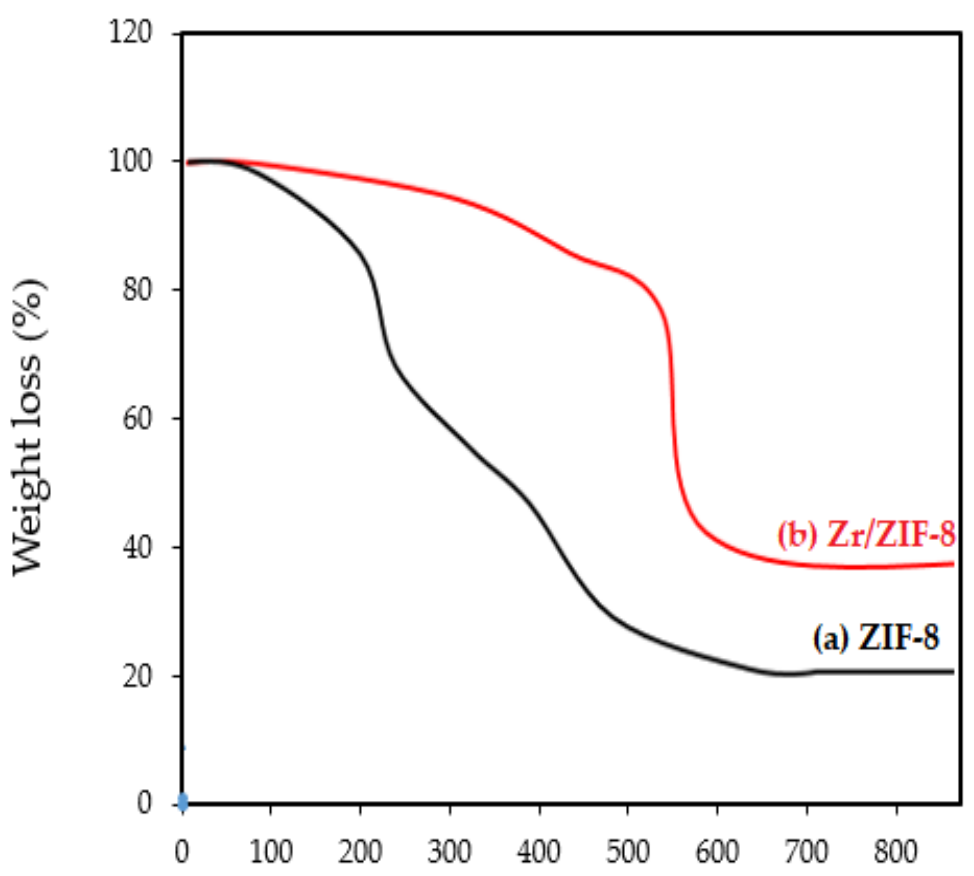

Temperature (K)

Figure 11. Thermal stability curve of (a) ZIF-8 and (b) Zr/ZIF-8.

\section{Catalytic Activity}

After catalyst characterization, the catalytic activity of the novel materials was compared with ZIF-8 for the synthesis of chloromethyl ethylene carbonate from $\mathrm{CO}_{2}$ and epichlorohydrin under solvent-free conditions. It is interesting to note that the combination of acid and basic sites (Lewis and Brönsted site) existing in the MOF catalyst may improve the catalytic activity of both samples. 
The reactions were carried out under the same conditions of $353 \mathrm{~K}$ reaction temperature, 8 bar $\mathrm{CO}_{2}$ pressure, $10 \%(w / w)$ catalyst loading, $8 \mathrm{~h}$ reaction time, and $350 \mathrm{rpm}$ of stirring speed.

From the Table 2, it follows that at optimum $\mathrm{CO}_{2}$ pressure of 8 bar, reaction time of $8 \mathrm{~h}$, catalyst loading of $10 \% w / w$, and variable temperature, Zr/ZIF-8 exhibits a higher catalytic activity than ZIF-8 (Zr/ZIF-8: 93\%, 86\%, 76\%; and ZIF-8: 77\%, 74\%, 52\%) for conversion, selectivity, and yield respectively at the same reaction conditions. The presence of acid and/or basic site in heterogeneous catalyst has significantly catalyzed the reaction of $\mathrm{CO}_{2}$ and $\mathrm{ECH}$ to produce $\mathrm{CMEC}$ [42].

Table 2. Summary of catalytic performance of ZIF-8 and Zr/ZIF-8 for coupling reaction of $\mathrm{CO}_{2}$ and epichlorohydrin to produce chloromethyl ethylene carbonate.

\begin{tabular}{cccccc}
\hline Entry & Catalyst & T (K) & Conversion (\%) & Selectivity (\%) & Yield (\%) \\
\hline 1 & ZIF-8 & 323 & 65 & 57 & 37 \\
2 & ZIF-8 & 333 & 69 & 64 & 44 \\
3 & ZIF-8 & 343 & 73 & 69 & 49 \\
4 & ZIF-8 & 353 & 77 & 74 & 52 \\
5 & ZIF-8 & 363 & 81 & 71 & 51 \\
6 & ZIF-8 & 373 & 85 & 69 & 49 \\
7 & Zr/ZIF-8 & 323 & 80 & 67 & 58 \\
8 & Zr/ZIF-8 & 333 & 86 & 74 & 64 \\
9 & Zr/ZIF-8 & 343 & 90 & 80 & 70 \\
10 & Zr/ZIF-8 & 353 & 93 & 86 & 76 \\
11 & Zr/ZIF-8 & 363 & 95 & 85 & 75 \\
12 & Zr/ZIF-8 & 373 & 97 & 82 & 72 \\
\hline
\end{tabular}

\subsection{Effect of Different Heterogeneous Catalysts}

Catalysts are very important parts of any chemical reaction; they contain active sites, which are able to speed up the kinetics of chemical reaction by reducing the activation energy. Different types of homogenous and heterogeneous catalysts have been synthesized to catalyze the reaction of $\mathrm{CO}_{2}$ and epoxide to produce corresponding organic carbonates. In order to assess the stability and effectiveness of the samples, the catalytic activity of both ZIF- 8 and Zr/ZIF-8 was investigated in the synthesis of chloromethyl ethylene carbonate from $\mathrm{CO}_{2}$ and epichlorohydrin. Table 2 shows the effects of the two catalysts for the conversion of epichlorohydrin, selectivity and yield of chloromethyl ethylene carbonate. The catalysts were synthesized using solvothermal method as per standard procedures. The samples were heat-treated at about $373 \mathrm{~K}$ in order to enhance an improved catalytic activity and were labelled as ZIF-8 and Zr/ZIF-8 for pure and doped samples, respectively. The reaction of $\mathrm{CO}_{2}$ and $\mathrm{ECH}$ to produce $\mathrm{CMEC}$ was carried out in a $25 \mathrm{~mL}$ high-pressure reactor at $353 \mathrm{~K}$ reaction temperature, 8 bar $\mathrm{CO}_{2}$ pressure, $10 \%$ catalyst loading, and $8 \mathrm{~h}$ reaction time. It can be seen from Table 2 that when ZIF-8 was used to catalyze the reaction of $\mathrm{CO}_{2}$ and $\mathrm{ECH}$, the conversion of $\mathrm{ECH}$, selectivity, and the yield of CMEC were $77 \%, 74 \%$, and $52 \%$ respectively. However, incorporating zirconium into ZIF-8 has significantly increased catalytic performance of Zr/ZIF-8 with the conversion of ECH, selectivity and the yield of CMEC being $93 \%, 86 \%$, and $76 \%$ respectively, although, the presence of side products were reported in both reactions by GC analysis. These side products include 3-chloropropane 1,2-diol and 2,5-bis (chloromethyl)-1,4-dioxane.

With similar pore spaces and same embedded Lewis acid metal sites in both ZIF-8 and Zr/ZIF-8 catalysts, the increase in the catalytic activity of $\mathrm{Zr} / \mathrm{ZIF}-8$ as shown in Figure 12, may be ascribed to high $\mathrm{CO}_{2}$ affinity via the introduction of zirconium into MOF, which has significantly increased those pore spaces of ZIF-8 [55]. A fine balance of proximity between pure and Zr-doped MOF was critically examined by Demir and research group. Their experimental results in the solvent-free coupling reaction of $\mathrm{ECH}$ and $\mathrm{CO}_{2}$ to produce epichlorohydrin carbonate (ECHC) concluded that $79.6 \%$ yield of ECHC and $97.3 \%$ selectivity were achieved after $2 \mathrm{~h}$ using Zr-MOF catalyst (Zr/MOF-53). It is however 
interesting to note that GC analysis of the product of Zr/ZIF-8 identified 3-chloropropane-1,2-diol (diols of epichlorohydrin-14.2\%) as the main reaction by-products.

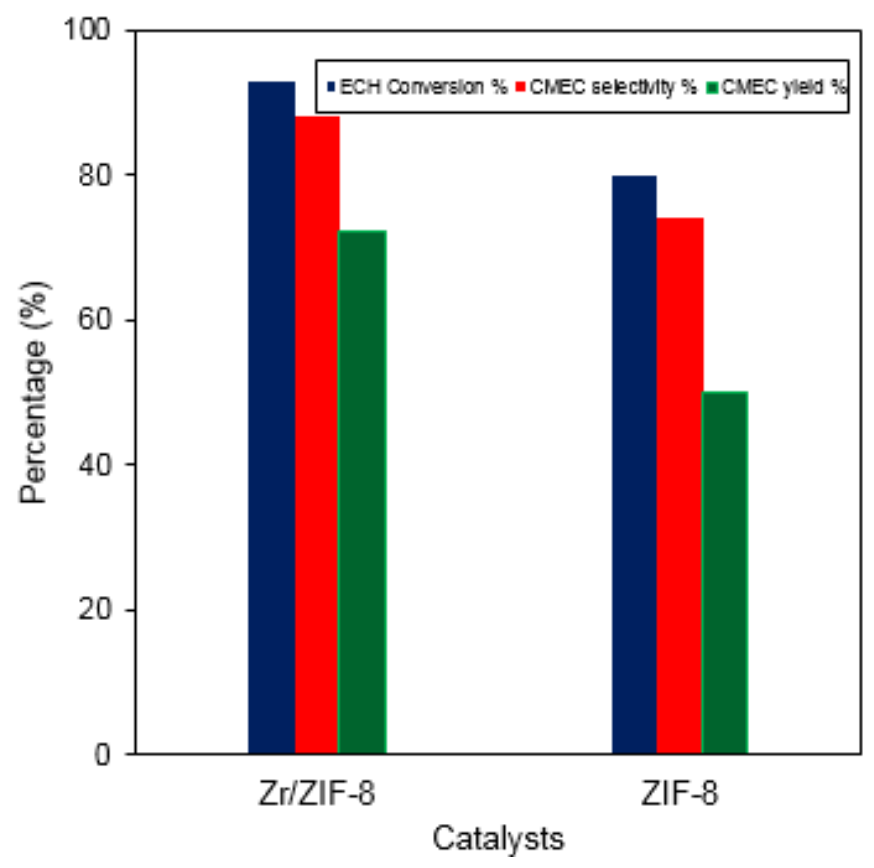

Figure 12. Effect of different catalysts on the cycloaddition reaction of epichlorohydrin (ECH) and carbon dioxide $\left(\mathrm{CO}_{2}\right)$ to produce chloromethyl ethylene carbonate (CMEC) with reaction conditions of $353 \mathrm{~K}$ reaction temperature, 8 bar $\mathrm{CO}_{2}$ pressure, $10 \%$ catalyst loading, $8 \mathrm{~h}$ reaction time, and $350 \mathrm{rpm}$ of stirring speed.

To affirm the superior catalytic performance of Zr/ZIF-8 over ZIF-8, nitrogen adsorption and desorption isotherms of the two frameworks were collected and presented in Table 1. Zr/ZIF-8 showed higher $\mathrm{CO}_{2}$ adsorption capacity which explains in part the improved catalytic performance.

\subsection{Effect of Temperature}

The cycloaddition reaction of $\mathrm{CO}_{2}$ and epoxide can be referred to as exothermic in nature. The influence of temperature on the cycloaddition of $\mathrm{CO}_{2}$ to $\mathrm{ECH}$ to produce $\mathrm{CMEC}$ was investigated between temperature ranges of 323 to $373 \mathrm{~K}$. All experiments were conducted with optimized reaction conditions, which were determined during our previous studies with a $10 \%$ catalyst loading and 8 bar $\mathrm{CO}_{2}$ pressure for $8 \mathrm{~h}$ and a stirring speed of $350 \mathrm{rpm}$. Table 2 shows the catalytic performance of $\mathrm{Zr} / \mathrm{ZIF}-8$ and ZIF- 8 as a function of temperature, $\mathrm{CO}_{2}$ pressure, reaction time, and catalyst loading. It can be depicted from Figure 13 that the conversion of epichlorohydrin, selectivity and yield of CMEC were temperature-dependent. Generally speaking, variation in temperature has similar trends in the catalytic activity of both frameworks; the conversion of epichlorohydrin, the selectivity and yield of CMEC increases as temperature increases from 323 to $353 \mathrm{~K}$. However, incorporating zirconium into ZIF-8 has significantly improved the performance of Zr/ZIF-8 with the conversion of ECH, selectivity and yield of CMEC as $93 \%, 86 \%$, and $76 \%$ respectively, while ZIF- 8 gave a conversion of ECH, selectivity and yield of CMEC as $77 \%, 74 \%$, and $52 \%$, respectively, under the same optimum reaction temperature.

Further increase in reaction temperature beyond $353 \mathrm{~K}$ was unfavorable to selectivity and yield of CMEC in both systems. A slight decrease of the CMEC yield (from $76 \%$ to $75 \%$; $\mathrm{Zr} / \mathrm{ZIF}-8$ and $52 \%$ to $51 \%$; ZIF-8) was observed upon an increase in temperature. This may be due to the formation of diols and dimers of epichlorohydrin [56] and a small amount of by-products such as polymerized CMEC could also affect the yield. Adeleye et al. [57] reported that the increase in the reaction temperature caused a decrease in carbonate yield, due to the decomposition of the catalyst at a higher temperature. 
Kim et al. [58] also concluded that the reaction temperature for optimal performance is dependent on the nature of the catalyst employed. Therefore, for this set of experiments, the optimized reaction temperature for both frameworks in the synthesis of chloromethyl ethylene carbonate was $353 \mathrm{~K}$. All the subsequent experiments for the chloromethyl ethylene carbonate were conducted at $353 \mathrm{~K}$.

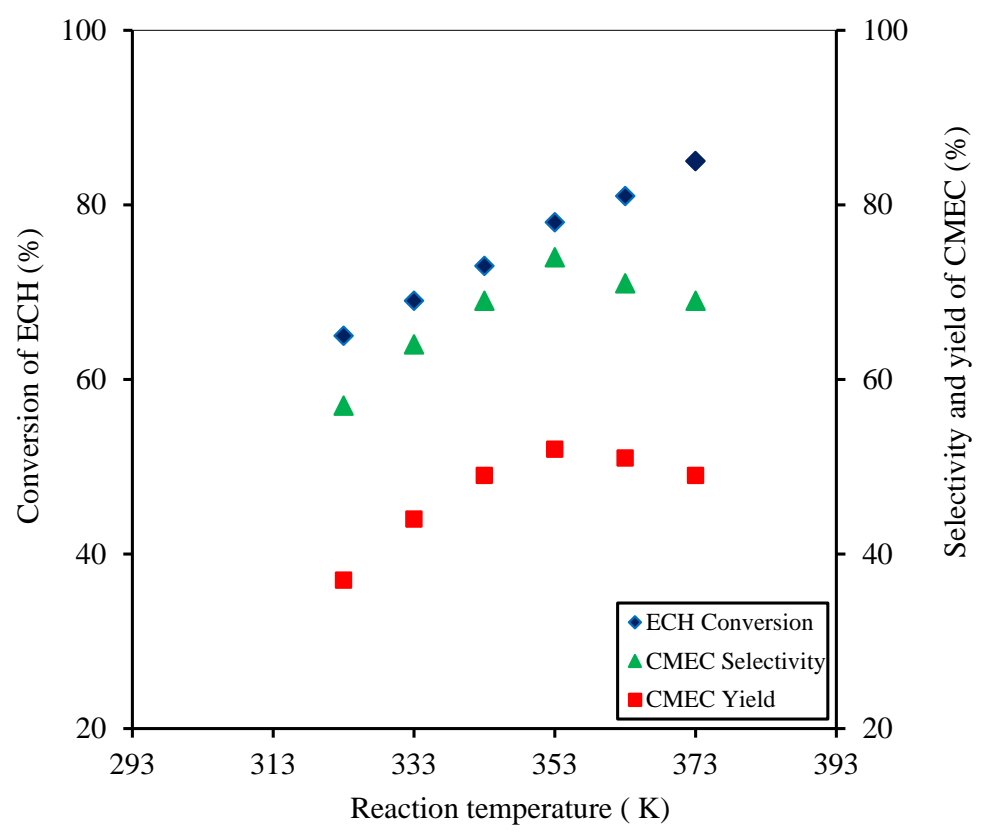

(a) ZIF-8

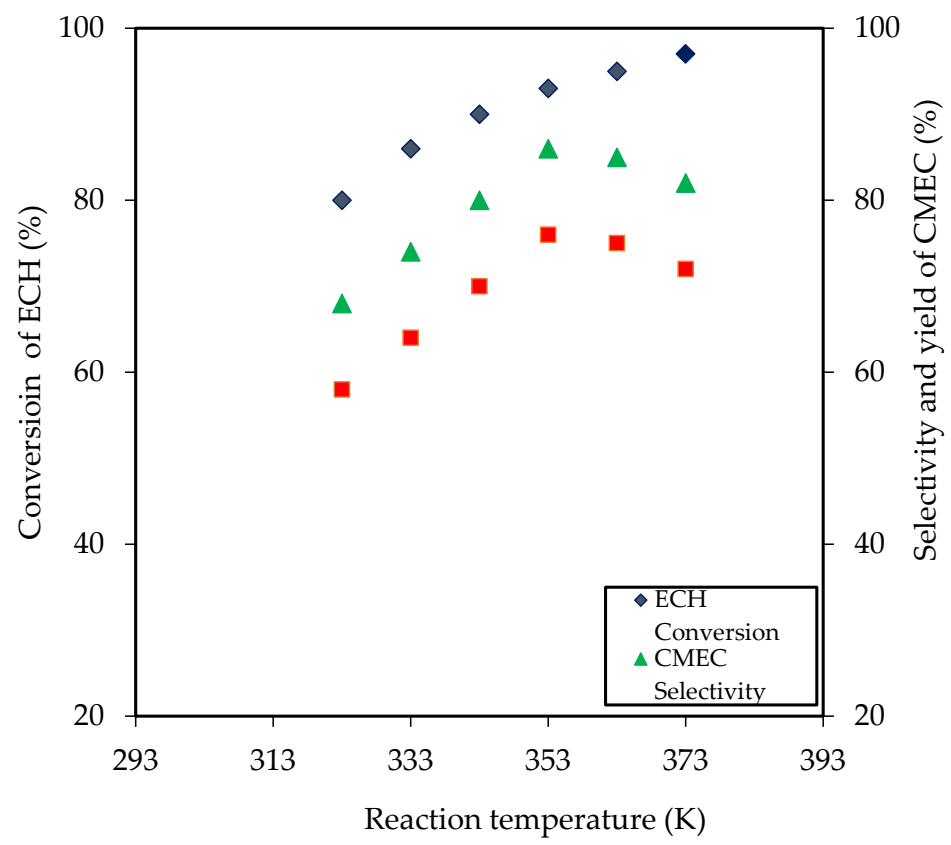

(b) Zr/ZIF-8

Figure 13. Temperature dependence on conversion of ECH versus selectivity and yield of CMEC. Experimental conditions: catalyst (a) ZIF-8 and (b) Zr/ZIF-8; catalyst loading 10\% (w/w); reaction time $8 \mathrm{~h} ; \mathrm{CO}_{2}$ pressure $8 \mathrm{bar}$; stirring speed $350 \mathrm{rpm}$. 


\subsection{Effect of $\mathrm{CO}_{2}$ Pressure}

$\mathrm{CO}_{2}$ pressure is another important factor influencing the cycloaddition of $\mathrm{CO}_{2}$ to epoxides. The pressure of carbon dioxide has been established as one of the most crucial factors affecting the conversion, yield, and selectivity of cyclic carbonate [59]. The reaction of epichlorohydrin and $\mathrm{CO}_{2}$ to produce chloromethyl ethylene carbonate was examined by varying the $\mathrm{CO}_{2}$ pressures. For this study, the experiments were carried out at $353 \mathrm{~K}, 10 \%$ catalyst loading, and $350 \mathrm{rpm}$ for $8 \mathrm{~h}$.

The selectivity and yield of CMEC was found to increase steadily from $67 \%$ and $58 \%$ to $86 \%$ and $76 \%$, respectively, as the $\mathrm{CO}_{2}$ pressure increases from 2 to 8 bar. These results indicate that the catalytic performance of the $\mathrm{Zr} / \mathrm{ZIF}-8$ depends on the concentration of available $\mathrm{CO}_{2}$ at the reactive sites. Similar variation was observed in the catalytic activity of the two frameworks with changing $\mathrm{CO}_{2}$ pressure where the selectivity and yield of CMEC increased from $57 \%$ and $37 \%$ to $77 \%$ and $52 \%$, respectively, at the same pressure of 8 bar of $\mathrm{CO}_{2}$ as in the case of $\mathrm{Zr} / \mathrm{ZIF}-8$.

Figure 14 demonstrates the dependence of $\mathrm{CO}_{2}$ pressure on the yield of CMEC. It can be observed from the graph that the CMEC yield increased with increasing pressure, the maximum of the CMEC yield was reached at 8 bar. By increasing the $\mathrm{CO}_{2}$ pressure more than 8 bar, a negative effect was observed on both reaction systems, where both yield and conversion experience a slight drop. Wang et al. [60] observed that the introduction of too much $\mathrm{CO}_{2}$ dissolves in epoxide may result in the formation of $\mathrm{CO}_{2}$-epoxide complex, and retards the interaction resulting in a lower conversion. Similar results were also reported by Onyenkeadi et al. [61], where the introduction of higher pressure of $\mathrm{CO}_{2}$ dissolved in the epoxide and becomes an unfavorable factor due to the difficulty of separating $\mathrm{CO}_{2}$ and $\mathrm{ECH}$. This condition inhibits the reaction between $\mathrm{ECH}$ and catalyst, thus resulting in lower yield [62]. Liang et al. [63] also reported that many diols and dimers of epichlorohydrin were produced as side products at high pressure. Based on the experimental results and theoretical study, it can be concluded that 8 bar $\mathrm{CO}_{2}$ pressure was the optimum and all subsequent experiments for the CMEC synthesis were carried out at a $\mathrm{CO}_{2}$ pressure of 8 bar.

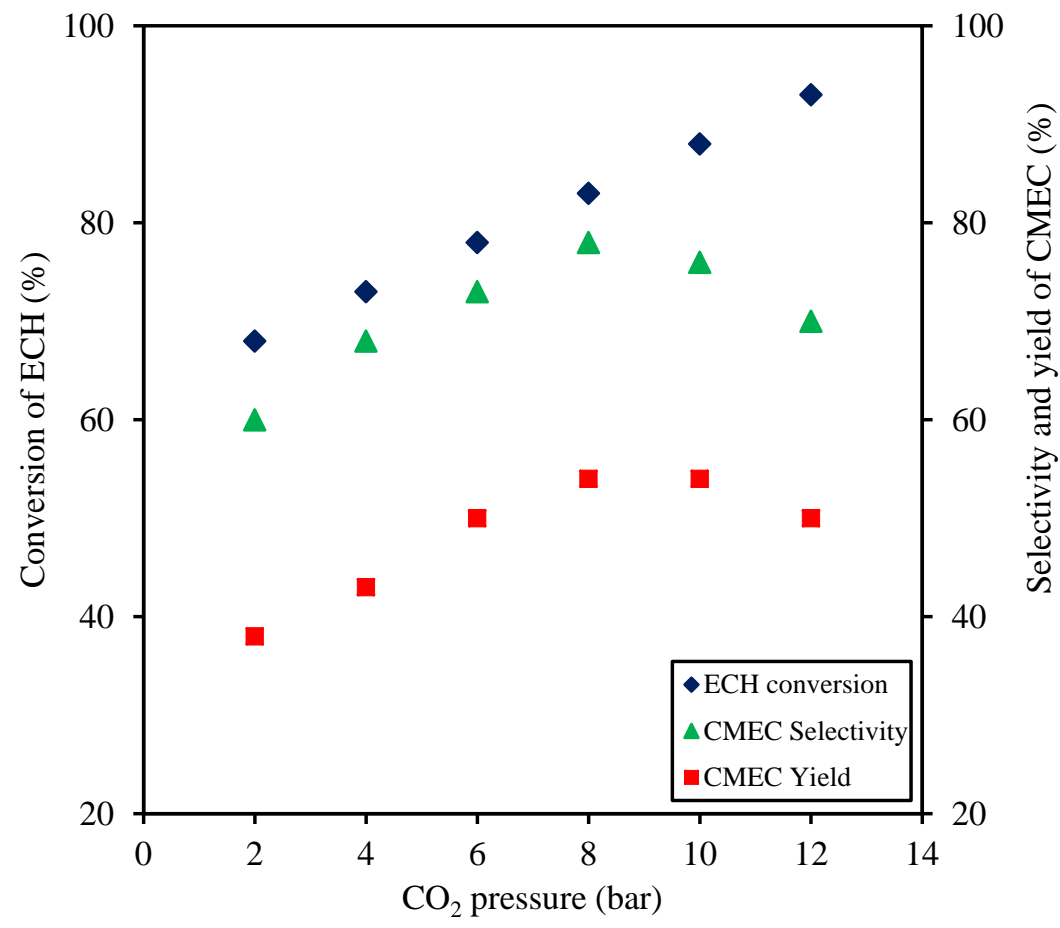

(a) ZIF-8

Figure 14. Cont. 


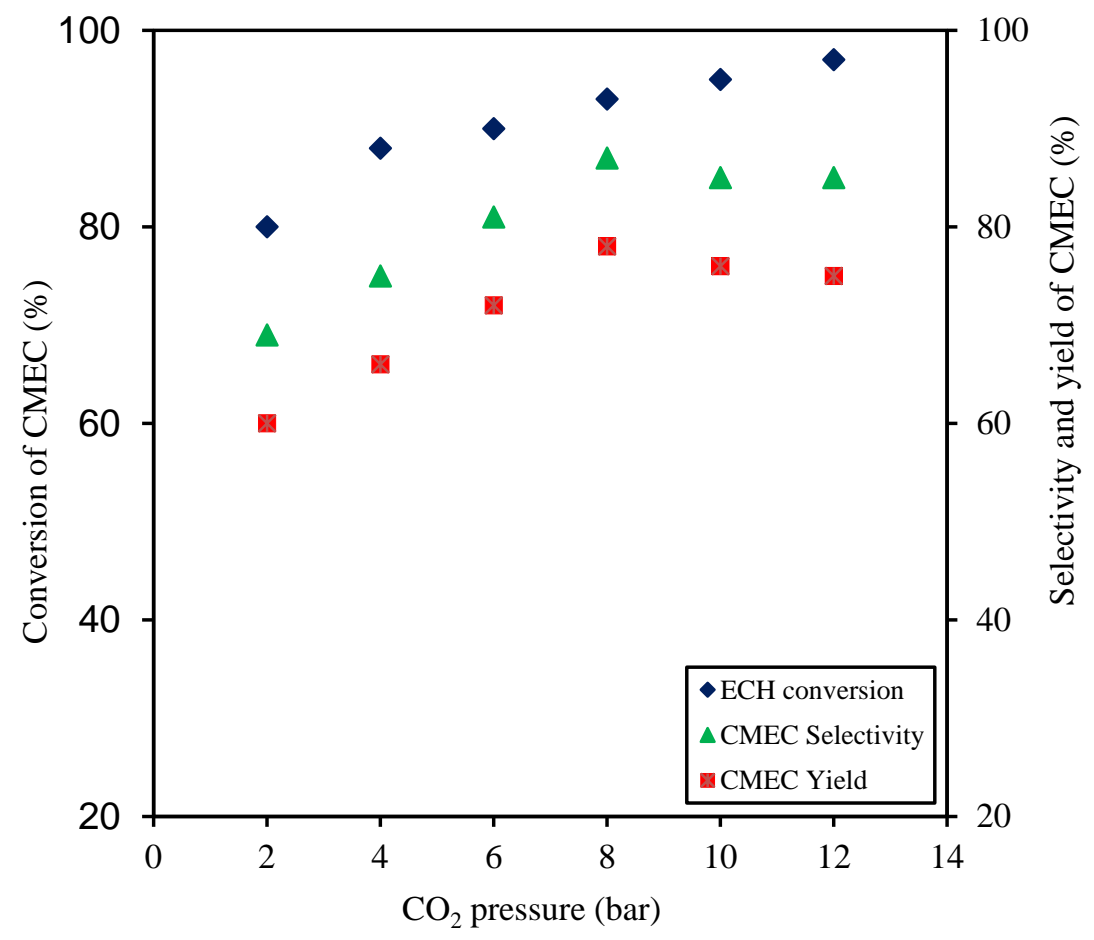

(b) $\mathrm{Zr} / \mathrm{ZIF}-8$

Figure 14. Pressure dependence on conversion of ECH versus selectivity and yield of CMEC. Experimental conditions: catalyst (a) ZIF-8 and (b) Zr/ZIF-8; catalyst loading 10\% (w/w); reaction time $8 \mathrm{~h}$; reaction temperature $353 \mathrm{~K}$; stirring speed $350 \mathrm{rpm}$.

\subsection{Influence of Reaction Time}

The effect of varying the reaction time on the yield of CMEC was investigated by carrying out a set of coupling reaction of $\mathrm{CO}_{2}$ and epichlorohydrin using both ZIF- 8 and $\mathrm{Zr} / \mathrm{ZIF}-8$ catalysts. For this study, all experiments were conducted at $353 \mathrm{~K}$ and 8 bar $\mathrm{CO}_{2}$ pressure with $10 \%(w / w)$ catalyst loading of ZIF-8 and Zr/ZIF-8. Figure 15 demonstrates the influence of reaction time on CMEC yield and selectivity. The results shown on the graph illustrates that the yield increased continuously at the beginning and reached $76 \%$ and $52 \%$ within $8 \mathrm{~h}$ for Zr/ZIF- 8 and ZIF- 8 , then decreased to $75 \%$ and $51 \%$ respectively, indicating that a slight change in the reaction condition can influence the product formation in a reaction. Similarly, the conversion of ECH was observed to increase from 353 to $366 \mathrm{~K}$ when the reaction time was increased from 2 to $8 \mathrm{~h}$. However, when the reaction time was increased further to $10 \mathrm{~h}$ and above, a progressive decrease in conversion of $\mathrm{ECH}$ was recorded. A similar observation was previously reported in the conversion of ECH to chloropropene carbonate with Zn-ZIF-67 by Adeleye et al. [64]. According to him, conversion of epoxides reaches an equilibrium plateau at optimum reaction time. This phenomenon is referred to as induction period. The induction period is attained when the $\mathrm{CO}_{2}$ and epoxides sufficiently diffuse into the catalytic frameworks of the ZIF-material to reach the active sites of the catalyst and then be converted to the organic carbonate. Beyond the induction period, low conversion of epoxides as well organic carbonates may be observed. From Figure 15, it can be concluded that prolonged reaction time produces lesser ECH conversion and consequently lesser CMEC yield and selectivity. Based on the experimental results and theoretical study, the reaction time of $8 \mathrm{~h}$ was considered the optimum for ZIF-8 and Zr/ZIF-8. 


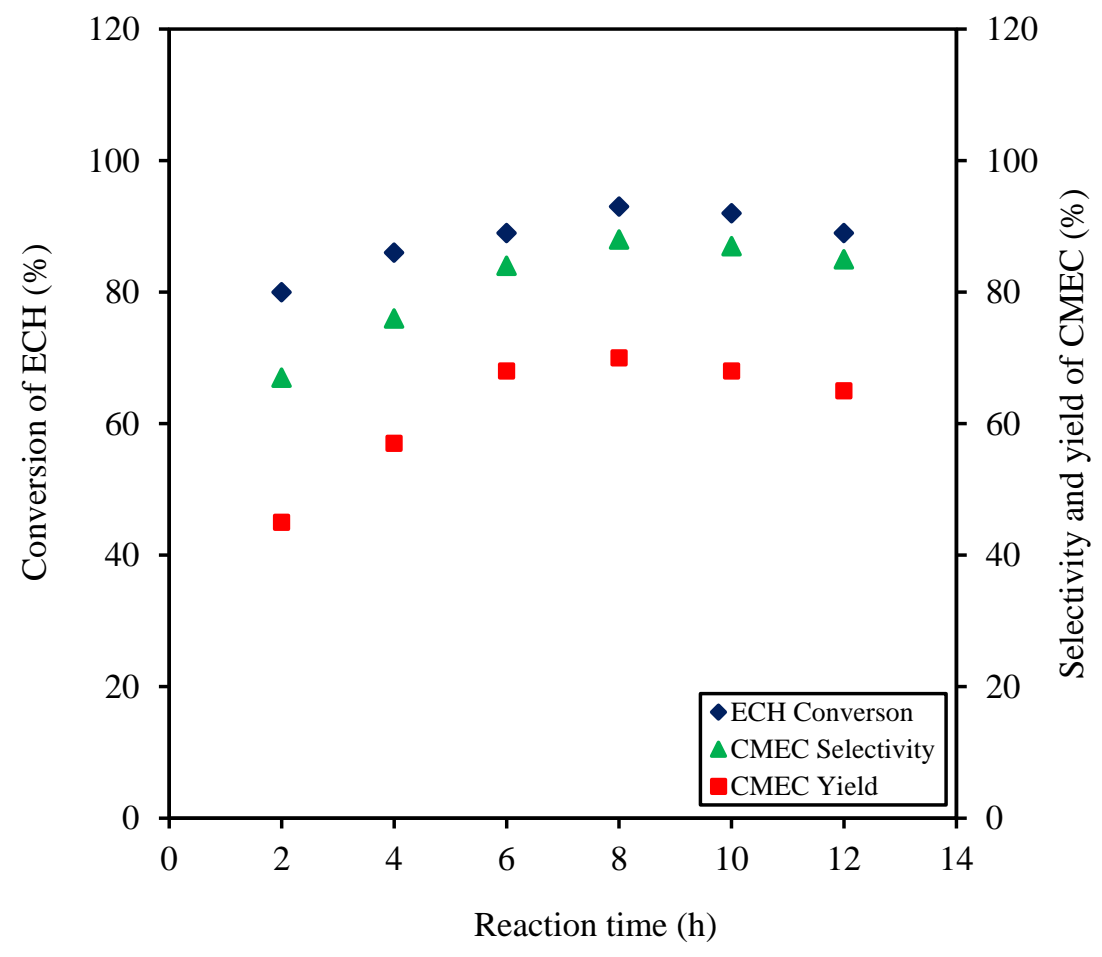

Figure 15. Time dependence on conversion of ECH versus selectivity and yield of CMEC. Experimental conditions: catalyst $\mathrm{Zr} / \mathrm{ZIF}-8$; catalyst loading $10 \%(w / w)$; reaction temperature $353 \mathrm{~K} ; \mathrm{CO}_{2}$ pressure 8 bar; stirring speed $350 \mathrm{rpm}$.

\subsection{Effect of External Mass Transfer in Heterogeneous Catalytic Processes}

Mass transfer limitations play significant roles in chemical reactions by controlling the rate of reaction towards the desired product. In homogenous catalytic reaction, the effect of mass transfer between the phases is mostly negligible. However, in a heterogeneous catalytic reaction, the reaction rate significantly relies on the mass or diffusion between these phases. Mass transfer is typically higher in porous solid or fine particles of nanoscale than large nonporous catalyst [65], transfer of material from the exterior to the interior of a particle happens through pores that open to the external surface, which provides access to the interior of the crystallite material [65]. A typical example is zeolitic imidazolate framework (ZIF-8).

In the heterogeneous catalytic conversion of $\mathrm{CO}_{2}$ and epoxide, the internal and external gradient of transport materials between system phases lowers the activity and selectivity of the catalyst towards the desired product [66]. It is important to know that when designing a new catalyst and directing such a catalyst to be selective towards a particular desired product mass transfer resistance and the kinetics are key functions [66]. In cycloaddition reaction of $\mathrm{CO}_{2}$ with $\mathrm{ECH}$, the physicochemical properties of the catalyst and the operating conditions all have a direct effect on the activity of the catalyst as well as the quality of CMEC formed [67]. When a chemical reaction occurs on an active surface, intraparticle diffusion takes place through the pores and the film surrounding the solid catalyst [67].

The coupling reaction of $\mathrm{ECH}$ with $\mathrm{CO}_{2}$ to produce chloromethyl ethylene carbonate is an exothermic reaction. In order to reduce or eliminate the effects of mass transfer resistance, it is recommended to employ a highly porous heterogeneous catalyst [68]. The influence of mass transfer on the reaction of $\mathrm{ECH}$ and $\mathrm{CO}_{2}$ to synthesize $\mathrm{CMEC}$ at $353 \mathrm{~K}$ reaction temperature for $8 \mathrm{~h}$ with a range of stirring speed between 320 and $550 \mathrm{rpm}$ in an autoclave reactor. It was observed that there was no significant change in the conversion of ECH ( 93), selectivity ( 86), and the yield of CMEC ( 76) when the stirrer speed was maintained above $330 \mathrm{rpm}$. Therefore, it was concluded that there was no effect of external mass transfer resistance on the experimental conditions. 


\subsection{Effect of Catalyst Loading}

To investigate the influence of catalyst loading on the CMEC synthesis, several number of experiments were performed by varying the molar ratio of both ZIF-8 and Zr/ZIF-8 catalyst to ECH. For this study, all experiments were conducted at $353 \mathrm{~K}$ and 8 bar $\mathrm{CO}_{2}$ pressure for $8 \mathrm{~h}$. The results of varying catalyst loading are presented in Figure 16. It can be observed from the graph that by increasing the catalyst loading, there was a corresponding increase in ECH conversion, yield, and selectivity of CMEC. For example, for the experiments conducted with catalyst loadings from $2.5 \%-7.5 \%$, there was a significant increase in ECH conversion, yield, and selectivity of CMEC. Also, for the experiment conducted at $10 \%(w / w)$ of catalyst loading, there was a sharp increase of ECH conversion, yield, and selectivity of CMEC from $90 \%-96 \%, 45 \%-56 \%$, and $73 \%-79 \%$, respectively. According to Maeda et al. [68], the decrease in epoxide conversion may be ascribed to a decrease in the substrate concentration around the pore cavities of the catalyst at higher catalyst loading. This effect neutralizes the Brönsted acid centers of the catalyst, thereby preventing the interaction between the acidic sites of the catalyst and the oxygen atom of epoxide from the ring opening. This consequently reduces the epoxides conversion to organic carbonates. Considering the percentage error of $\pm 2 \%$, it can be concluded that the number of active sites for $\mathrm{ECH}$ and $\mathrm{CO}_{2}$ to react and produce $\mathrm{CMEC}$ was large enough at $10 \%(w / w)$ catalyst loading. From the results obtained with respect to catalyst loading, $10 \%(w / w)$ was the optimum. From the experimental results for both ZIF- 8 and $\mathrm{Zr} / \mathrm{ZIF}-8$ catalysts, it is satisfactory to conclude that $10 \%(w / w)$ catalyst loading was considered the optimum and further experiments were carried out at $10 \%(w / w)$ catalyst loading.

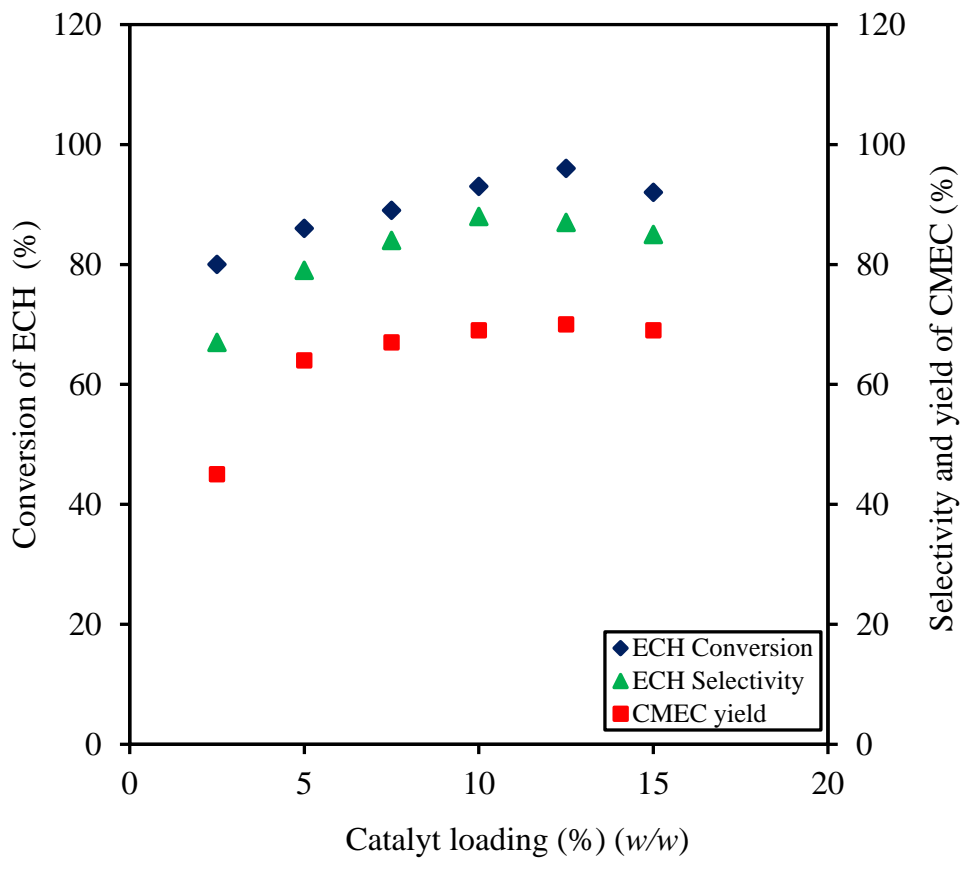

Figure 16. Catalyst loading dependence on conversion of ECH versus selectivity and yield of CMEC. Experimental conditions: catalyst $\mathrm{Zr} / \mathrm{ZIF}-8$; reaction temperature $353 \mathrm{~K}$, (w/w); reaction time $8 \mathrm{~h} ; \mathrm{CO}_{2}$ pressure 8 bar; stirring speed $350 \mathrm{rpm}$.

\subsection{Effect of Reaction Conditions on Catalysts Selectivity to Chloromethyl Ethylene Carbonate}

Figure 13a,b shows the effect of varying reaction temperature on catalysts' selectivities towards CMEC. For example, it can be observed that when the temperature was increased from 50 to $80^{\circ} \mathrm{C}$, both catalysts show a corresponding increase in selectivities from $68 \%$ and $50 \%$ to $86 \%$ and $74 \%$, respectively. However, when the temperature was increased beyond the $353 \mathrm{~K}$, a marginal decrease in selectivities was observed in both frameworks, demonstrating that the $353 \mathrm{~K}$ was the optimum temperature for the 
reaction. Meanwhile, the gas chromatography-mass spectroscopy (GC-MS) analysis of the samples shows that $17.3 \%$ of 2,5-bis (chloromethyl)-1,4-dioxane (by-product) formed at $353 \mathrm{~K}$, this may explain in part why a drop in catalysts' selectivities was recorded for both samples. Similar results and by-product have been previously reported with ZIF-8 by Carron et al. [69]. They also agree that almost $100 \%$ selectivity of ZIF-8 to chloropropene carbonate was achieved at a temperature of $393 \mathrm{~K}$, but decreased to $78.6 \%$ when the temperature was increased to $403 \mathrm{~K}$.

In addition to the effect of temperature on catalysts' selectivities, the influence of varying $\mathrm{CO}_{2}$ pressure on catalysts' selectivities was also investigated. According to Figure 14a,b, the selectivity of the catalysts towards CMEC was found to increase steadily from $67 \%$ and $58 \%$ to $86 \%$ and $76 \%$, respectively, as the $\mathrm{CO}_{2}$ pressure was increased from 2 to 8 bar. These results indicates that the activity and selectivity of both catalysts were influenced by the concentration of available $\mathrm{CO}_{2}$ at the reactive sites. Although, similar effect was observed in the responses of both catalysts to variation in $\mathrm{CO}_{2}$ pressure, however, the results show that Zr/ZIF-8 has higher selectivity than the ZIF-8 catalyst, where the selectivity of both catalysts increased from $69 \%$ and $60 \%$ to $87 \%$ and $77 \%$, respectively, for Zr/ZIF- 8 and ZIF-8catalysts. Concersely, both samples experienced decline in selectivities from $87 \%$ and $77 \%$ to $85 \%$ and $70 \%$ for ZIF- 8 and $\mathrm{Zr} / \mathrm{ZIF}-8$, respectively, when the $\mathrm{CO}_{2}$ pressure was increased beyond the optimum level of 8 Bar.

Miralda et al. [70], further argues that ZIF-8 is a dual-functional catalyst with both acidic and basic sites that have been associated with the Lewis acid $\mathrm{Zn}^{2+}$ ions and the basic imidazole groups, respectively. This bifunctional characteristic enhances the catalyst selectivity for cycloaddition reaction. In a separate report, Miralda et al. [70], also ascertained that it is likely that Lewis acid sites associated with $\mathrm{Zn}^{2+}$ ions in the ZIF-8 framework play the vital role in catalyzing the reaction of epichlorohydrin and $\mathrm{CO}_{2}$ to chloropropene carbonate. They further explained that the presence of basic nitrogen atoms of the imidazole ligand, probably, favours the adsorption and binding of $\mathrm{CO}_{2}$ as well as activation of the carbon-oxygen bonds in $\mathrm{CO}_{2}$. In agreement with other similar doped ZIF-8, the open metal centers in the $\mathrm{Zr} / \mathrm{ZIF}-8$ has the potential to easily activate the epoxides and the basic sites present in the frameworks. This could be the reason for the higher selectivity that were observed in the solvent-free $\mathrm{ECH}-\mathrm{CO}_{2}$ cycloaddition reactions under mild conditions. Comparatively, the higher selectivity of $\mathrm{Zr}$ /ZIF-8 than ZIF-8 towards CMEC may be attributed to the presence of zirconium (Zr). According to a 2019 publication by de Caro et al. [71], the effect of $\mathrm{Zr}$ doping on Mg-Al hydrotalcite, the catalyst has significantly increased its selectivity from $90 \%$ to $>99 \%$ towards glycerol carbonate (GC).

\subsection{Reusability of ZIF-8 Catalysts}

Reusability is an important and essential feature of any heterogeneous catalyst in order to be considered useful in industrial applications [71]. The influence of catalyst reusability on the catalytic properties of ZIF-8 and Zr/ZIF-8 in the cycloaddition reaction was investigated. The experiments were carried out in a high-pressure reactor at optimum reaction conditions, i.e., at $353 \mathrm{~K}, 8$ bar with fresh $10 \%$ $(w / w)$ ZIF- 8 catalyst loading, for $8 \mathrm{~h}$, and at a stirring speed of $350 \mathrm{rpm}$. The catalysts after Run 1 in the cycloaddition reaction were washed with ethanol and acetone, centrifuged, and oven-dried at $343 \mathrm{~K}$ for $12 \mathrm{~h}$ before reuse. The recovered catalysts were reused for up to 7 subsequent experiments following the same experimental procedure. ZIF-8 showed a progressive loss in catalytic activity after each run as shown in Figure 17, while Zr/ZIF-8 exhibited no loss of activity indicating the catalyst stability for cycloaddition reaction of $\mathrm{CO}_{2}$ epichlorohydrin. Yuan et al. [72] stated that the presence of dopant in ZIF-8 show that zirconium is more stable and resilient during the reaction. There was no significant change in the conversion of ECH, selectivity, and yield of CMEC using Zr/ZIF-8. Although, a very slight decrease in the yield of CMEC from $70 \%$ (fresh) to $69 \%$ (recycled) was observed. The low catalytic activity of the recycled $\mathrm{Zr} / \mathrm{ZIF}-8$ catalyst may be ascribed to formation of carbonaceous materials during the cycloaddition reaction as previously reported by Yuan et al. [72]. Furthermore, the XRD and FT-IR analyses results confirmed that $\mathrm{Zr} / \mathrm{ZIF}-8$ maintained its crystallinity throughout the reaction process. 


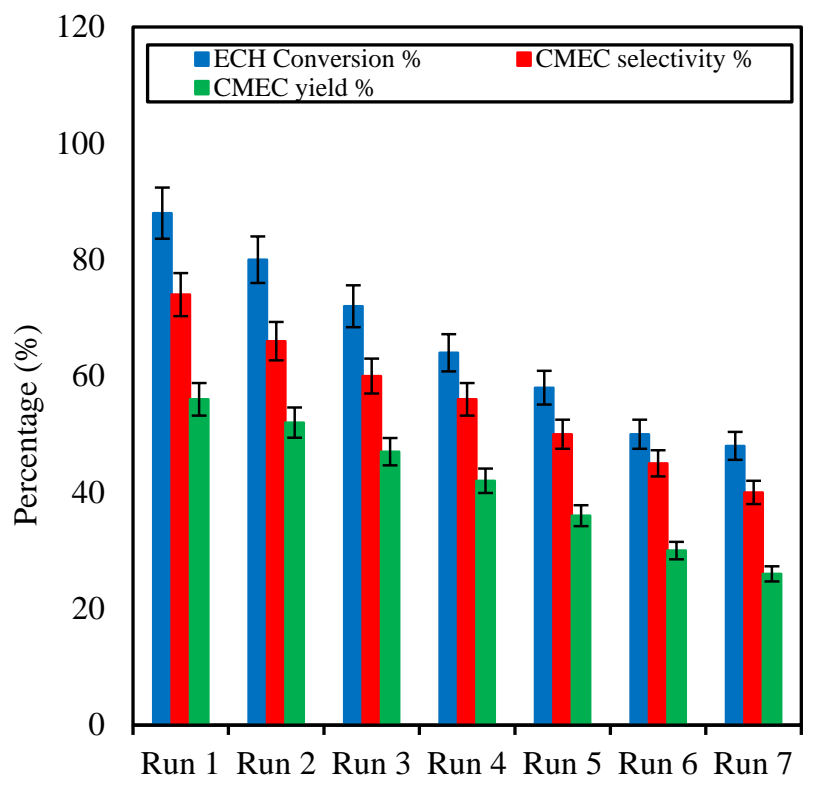

Recycle Number

(a) ZIF-8

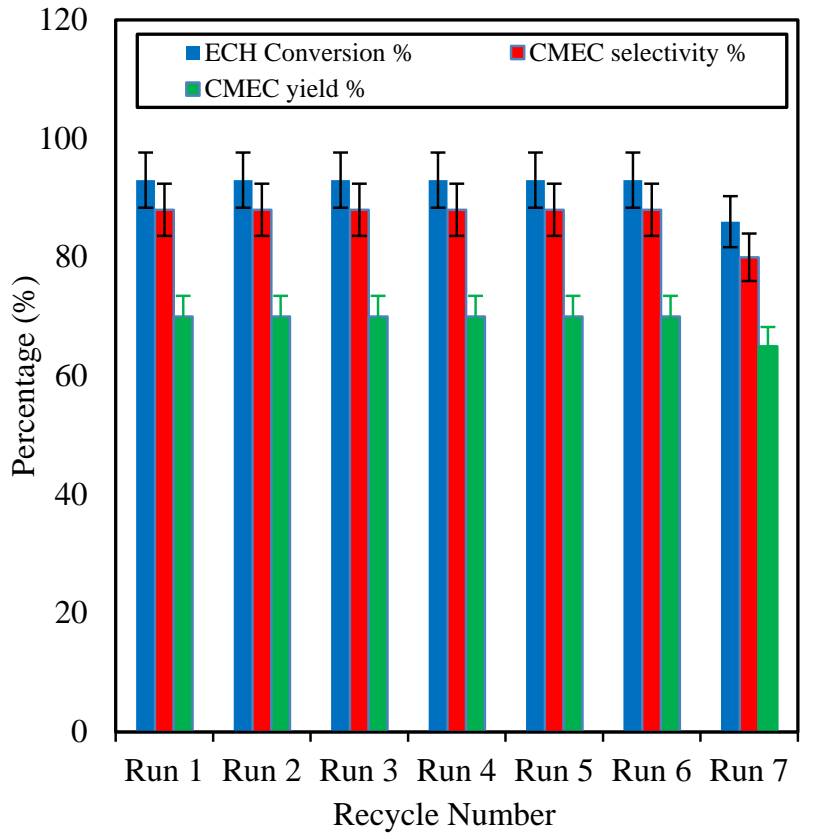

(b) Zr/ZIF-8

Figure 17. Catalyst reusability studies on conversion of $\mathrm{ECH}$, selectivity and yield of CMEC. Experimental conditions: catalyst: (a) ZIF-8 and (b) Zr/ZIF-8; catalyst loading 10\% (w/w); temperature $353 \mathrm{~K} ; \mathrm{CO}_{2}$ pressure 8 bar; reaction time $8 \mathrm{~h}$; stirring speed $350 \mathrm{rpm}$.

\section{Conclusions}

$\mathrm{Zr} / \mathrm{ZIF}-8$ has been successfully designed and assessed as a greener and highly efficient $\mathrm{CO}_{2}$-reduction catalyst for the synthesis of CMEC. Although ZIF-8 is criticized by many researchers as thermally unstable for the synthesis of organic carbonates from $\mathrm{CO}_{2}$ and epoxide, however, our 
experiments have confirmed that the introduction of zirconium into ZIF-8 could strengthen the weak functionality, making it tenable for large-scale industrial applications. Several authors have utilized zirconium to reinforce different kinds of MOF experiments in order to achieve optimum results. However, their attempts have been unsatisfactory, partly because a firm balance between the required percentage of zirconium dopant and their host molecules was not established for those particular experiments. It may also be worth mentioning that this work has utilized a $10 \%$ dopant of zirconium for such a tremendous catalytic activity of Zr/ZIF-8. The stability tests carried out on both samples show that Zr/ZIF-8 demonstrates higher stability compared with single metal ZIF-8.

It has been concluded from the experimental results that there is a direct relationship between variation in the reaction conditions and ECH conversion, CMEC yield, and selectivity. From the experimental results, it can be observed that Zr/ZIF-8 catalyst displayed high epoxide conversions and high selectivity to chloromethyl ethylene carbonate at $353 \mathrm{~K}$, without using any solvent or co-catalyst. Lewis acid copper (II) sites in the ZIF-8 frameworks promote adsorption of $\mathrm{CO}_{2}$ on the solid surface and its further conversion to CMEC. The activity of reused Zr/ZIF-8 catalyst showed consistent stability over seven subsequent runs. The optimum reaction condition for the experiments was found at $353 \mathrm{~K}$, 8 bar $\mathrm{CO}_{2}$ pressure, and $8 \mathrm{~h}$ using fresh $10 \%(w / w) \mathrm{Zr} / \mathrm{ZIF}-8$ catalyst loading for this reaction. Therefore, the development of a novel $\mathrm{Zr} / \mathrm{ZIF}-8$ catalyst for the synthesis of $\mathrm{CMEC}$ from $\mathrm{CO}_{2}$ and $\mathrm{ECH}$ provided an efficient and promising greener route for $\mathrm{CO}_{2}$ utilization.

Author Contributions: B.O.: main author and prepared the original draft. B.S.: Reviewed manuscript, gave comments, edited contents and supervised PhD student. All authors have read and agreed to the published version of the manuscript.

Funding: This research received no external funding.

Acknowledgments: Bisi Olaniyan is immensely grateful to the School of Engineering, LSBU, UK for partial financial assistance rendered throughout this research work.

Conflicts of Interest: The authors declare no conflict of interest.

\section{References}

1. Dai, W.L.; Luo, S.L.; Yin, S.F.; Au, C.T. The direct transformation of carbon dioxide to organic carbonates over heterogeneous catalysts. Appl. Catal. A Gen. 2009, 366, 2-12. [CrossRef]

2. Saada, R.; AboElazayem, O.; Kellici, S.; Heil, T.; Morgan, D.; Lampronti, G.I.; Saha, B. Greener synthesis of dimethyl carbonate using a novel tin-zirconia/graphene nanocomposite catalyst. Appl. Catal. B Environ. 2018, 226, 451-462. [CrossRef]

3. Baj, S.; Krawczyk, T.; Jasiak, K.; Siewniak, A.; Pawlyta, M. Catalytic coupling of epoxides and $\mathrm{CO}_{2}$ to cyclic carbonates by carbon nanotube-supported quaternary ammonium salts. Appl. Catal. A Gen. 2014, 488, 96-102. [CrossRef]

4. Adeleye, A.I.; Kellici, S.; Heil, T.; Morgan, D.; Vickers, M.; Saha, B. Greener synthesis of propylene carbonate using graphene-inorganic nanocomposite catalysts. Catal. Today 2015, 256, 347-357. [CrossRef]

5. Onyenkeadi, V.; Kellici, S.; Saha, B. Greener synthesis of 1,2-butylene carbonate from $\mathrm{CO}_{2}$ using graphene-inorganic nanocomposite catalyst. Energy 2018, 165, 867-876. [CrossRef]

6. Kathalikkattil, A.C.; Babu, R.; Tharun, J.; Roshan, R.; Park, D.W. Advancements in the Conversion of Carbon Dioxide to Cyclic Carbonates Using Metal Organic Frameworks as Catalysts. Catal. Surv. Asia 2015, 19, 223-235. [CrossRef]

7. Karagiaridi, O.; Lalonde, M.B.; Bury, W.; Sarjeant, A.A.; Farha, O.K.; Hupp, J.T. Opening ZIF-8: A catalytically active zeolitic imidazolate framework of sodalite topology with unsubstituted linkers. J. Am. Chem. Soc. 2012, 134, 18790-18796. [CrossRef]

8. Beyzavi, M.H.; Stephenson, C.J.; Liu, Y.; Karagiaridi, O.; Hupp, J.T.; Farha, O.K. Metal Organic Framework-Based Catalysts: Chemical Fixation of $\mathrm{CO}_{2}$ with Epoxides Leading to Cyclic Organic Carbonates. Front. Energy Res. 2015, 2, 1-10. [CrossRef]

9. Rimoldi, M.; Howarth, A.J.; Destefano, M.R.; Lin, L.; Goswami, S.; Li, P.; Hupp, J.T.; Farha, O.K. Catalytic Zirconium/Hafnium-Based Metal-Organic Frameworks. ACS Catal. 2017, 7, 997-1014. [CrossRef] 
10. Zhang, X.; Zhang, X.; Johnson, J.A.; Chen, Y.S.; Zhang, J. Highly Porous Zirconium Metal-Organic Frameworks with $\beta-\mathrm{UH}_{3}$-like Topology Based on Elongated Tetrahedral Linkers. J. Am. Chem. Soc. 2016, 138, 8380-8383. [CrossRef]

11. Jeong, H.-M.; Roshan, R.; Babu, R.; Kim, H.-J.; Park, D.-W. Zirconium-based isoreticular metal-organic frameworks for $\mathrm{CO}_{2}$ fixation via cyclic carbonate synthesis. Korean J. Chem. Eng. 2017, 35, 438-444. [CrossRef]

12. Yang, X.; Qiu, L.; Luo, X. ZIF-8 derived Ag-doped ZnO photocatalyst with enhanced photocatalytic activity. RSC Adv. 2018, 8, 4890-4894. [CrossRef]

13. Bai, Y.; Dou, Y.; Xie, L.-H.; Rutledge, W.; Li, J.-R.; Zhou, H.-C. Zr-based metal-organic frameworks: Design, synthesis, structure, and applications. Chem. Soc. Rev. 2016, 45, 2327-2367. [CrossRef] [PubMed]

14. Marshall, R.J.; Forgan, R.S. Postsynthetic Modification of Zirconium Metal-Organic Frameworks. Eur. J. Inorg. Chem. 2016, 2016, 4310-4331. [CrossRef]

15. Jin, Z.; Yang, H. Exploration of Zr-Metal-Organic Framework as Efficient Photocatalyst for Hydrogen Production. Nanoscale Res. Lett. 2017, 12, 850-854. [CrossRef] [PubMed]

16. Cavka, J.H.H.; Jakobsen, S.; Olsbye, U.; Guillou, N.; Lamberti, C.; Bordiga, S.; Lillerud, K.P.P. A New Zirconium Inorganic Building Brick Forming Metal Organic Frameworks with Exceptional Stability. J. Am. Chem. Soc. 2008, 130, 13850-13851. [CrossRef]

17. Jiang, M.; Cao, X.; Liu, P.; Zhang, T.; Zhang, J. ZIF-8@Polyvinylpyrrolidone Nanocomposites Based N-Doped Porous Carbon for Highly Efficient Oxygen Reduction Reaction in Alkaline Solution. J. Electrochem. Soc. 2016, 163, H459-H464. [CrossRef]

18. Gong, Q.; Luo, H.; Cao, D.; Zhang, H.; Wang, W.; Zhou, X. Efficient cycloaddition reaction of carbon dioxide with epoxide by Rhodamine based catalyst under 1 atm pressure. Bull. Korean Chem. Soc. 2012, 33, 1945-1948. [CrossRef]

19. Demir, S.; Usta, S.; Tamar, H.; Ulusoy, M. Solvent free utilization and selective coupling of epichlorohydrin with carbon dioxide over zirconium metal-organic frameworks. Microporous Mesoporous Mater. 2017, 244, 251-257. [CrossRef]

20. Schejn, A.; Aboulaich, A.; Balan, L.; Falk, V.; Lalevée, J.; Medjahdi, G.; Aranda, L.; Mozet, K.; Schneider, R. $\mathrm{Cu}^{2+}$-doped zeolitic imidazolate frameworks (ZIF-8): Efficient and stable catalysts for cycloadditions and condensation reactions. Catal. Sci. Technol. 2015, 5, 1829-1839. [CrossRef]

21. Thi Thanh, M.; Vinh Thien, T.; Thi Thanh Chau, V.; Dinh Du, P.; Phi Hung, N.; Quang Khieu, D. Synthesis of Iron Doped Zeolite Imidazolate Framework-8 and Its Remazol Deep Black RGB Dye Adsorption Ability. J. Chem. 2017, 2017, 5045973. [CrossRef]

22. Sakakura, T.; Kohno, K. The synthesis of organic carbonates from carbon dioxide. Chem. Commun. 2009, 2, 1312-1330. [CrossRef] [PubMed]

23. Al-Janabi, N.; Hill, P.; Torrente-Murciano, L.; Garforth, A.; Gorgojo, P.; Siperstein, F.; Fan, X. Mapping the $\mathrm{Cu}$-BTC metal-organic framework (HKUST-1) stability envelope in the presence of water vapour for $\mathrm{CO}_{2}$ adsorption from flue gases. Chem. Eng. J. 2015, 281, 669-677. [CrossRef]

24. Coşkun, S.; Taşçi, Z.; Ulusoy, M.; Yurdakoç, M. Catalytic conversion of carbon dioxide into cyclic carbonates by $\mathrm{Cu}(\mathrm{II})$ and $\mathrm{Ni}(\mathrm{II})$ acetylacetonates anchored onto Siral 80. Turk. J. Chem. 2014, 38, 600-610. [CrossRef]

25. Saada, R. Catalytic Conversion of Carbon Dioxide $\left(\mathrm{CO}_{2}\right)$ into Value Added Chemicals. Ph.D. Thesis, London South Bank University, London, UK, 2015.

26. Gallardo-Fuentes, S.; Contreras, R.; Isaacs, M.; Honores, J.; Quezada, D.; Landaeta, E.; Ormazábal-Toledo, R. On the mechanism of $\mathrm{CO}_{2}$ electro-cycloaddition to propylene oxides. J. $\mathrm{CO}_{2}$ Util. 2016, 16, 114-120. [CrossRef]

27. Nabipour, H.; Sadr, M.H.; Bardajee, G.R. Synthesis and characterization of nanoscale zeolitic imidazolate frameworks with ciprofloxacin and their applications as antimicrobial agents. New J. Chem. 2017, 41, 7364-7370. [CrossRef]

28. Fan, G.; Zheng, X.; Luo, J.; Peng, H.; Lin, H.; Bao, M.; Hong, L.; Zhou, J. Rapid synthesis of Ag/AgCl@ZIF-8 as a highly efficient photocatalyst for degradation of acetaminophen under visible light. Chem. Eng. J. 2018, 351, 782-790. [CrossRef]

29. Nordin, N.A.H.M.; Ismail, A.F.; Mustafa, A. Synthesis and preparation of asymmetric PSf/ZIF-8 mixed matrix membrane for $\mathrm{CO}_{2} / \mathrm{CH}_{4}$ separation. J. Teknol. (Sci. Eng.) 2014, 69, 73-76. [CrossRef]

30. Zhu, M.; Srinivas, D.; Bhogeswararao, S.; Ratnasamy, P.; Carreon, M.A. Catalytic activity of ZIF-8 in the synthesis of styrene carbonate from $\mathrm{CO}_{2}$ and styrene oxide. Catal. Commun. 2013, 32, 36-40. [CrossRef] 
31. Da Silva, J.D.S.F.; Malo, D.L.; Bataglion, G.A.; Eberlin, M.N.; Ronconi, C.M.; Alves, S.; De Sá, G.F. Adsorption in a fixed-bed column and stability of the antibiotic oxytetracycline supported on $\mathrm{Zn}$ (II)-[2-methylimidazolate] frameworks in aqueous media. PLoS ONE 2015, 10, 1371-1381.

32. Fang, Q.-R.; Makal, T.A.; Young, M.D.; Zhou, H.-C. Recent Advances in the Study of Mesoporous Metal-Organic Frameworks. Comments Inorg. Chem. 2010, 31, 165-195. [CrossRef]

33. Panchariya, D.K.; Rai, R.K.; Anil Kumar, E.; Singh, S.K. Core-Shell Zeolitic Imidazolate Frameworks for Enhanced Hydrogen Storage. ACS Omega 2018, 3, 167-175. [CrossRef] [PubMed]

34. Liu, J.; He, J.; Wang, L.; Li, R.; Chen, P.; Rao, X.; Deng, L.; Rong, L.; Lei, J. NiO-PTA supported on ZIF-8 as a highly effective catalyst for hydrocracking of Jatropha oil. Sci. Rep. 2016, 6, 1-11. [CrossRef] [PubMed]

35. Na, L.Y.; Hua, R.N.; Ning, G.L.; Ou, X.X. Nano/Micro HKUST-1 Fabricated by Coordination Modulation Method at Room Temperature. Science 2012, 28, 555-558.

36. Goyal, S.; Shaharun, M.S.; Kait, C.F.; Abdullah, B. Effect of monometallic copper on zeolitic imidazolate framework-8 synthesized by hydrothermal method. J. Phys. Conf. Ser. 2018, 1123, 6. [CrossRef]

37. Cychosz, K.A.; Guillet-Nicolas, R.; García-Martínez, J.; Thommes, M. Recent advances in the textural characterization of hierarchically structured nanoporous materials. Chem. Soc. Rev. 2017, 46, 389-414. [CrossRef]

38. Yin, H.; Kim, H.; Choi, J.; Yip, A.C.K. Thermal stability of ZIF-8 under oxidative and inert environments: A practical perspective on using ZIF-8 as a catalyst support. Chem. Eng. J. 2015, 278, 293-300. [CrossRef]

39. North, M.; Pasquale, R.; Young, C. Synthesis of cyclic carbonates from epoxides and $\mathrm{CO}_{2}$. Green Chem. 2010, 12, 1514-1539. [CrossRef]

40. Zanon, A.; Chaemchuen, S.; Mousavi, B.; Verpoort, F. 1 Zn-doped ZIF-67 as catalyst for the $\mathrm{CO}_{2}$ fixation into cyclic carbonates. J. $\mathrm{CO}_{2}$ Util. 2017, 20, 282-291. [CrossRef]

41. Pang, S.H.; Han, C.; Sholl, D.S.; Jones, C.W.; Lively, R.P. Facet-specific stability of ZIF-8 in the presence of acid gases dissolved in aqueous solutions. Chem. Mater. 2016, 28, 6960-6967. [CrossRef]

42. Zhou, K.; Mousavi, B.; Luo, Z.; Phatanasri, S.; Chaemchuen, S.; Verpoort, F. Characterization and properties of Zn/Co zeolitic imidazolate frameworks vs. ZIF-8 and ZIF-67. J. Mater. Chem. A 2017, 5, 952-957. [CrossRef]

43. Bosch, M.; Zhang, M.; Zhou, H. Increasing the Stability of Metal-Organic Frameworks. Adv. Chem. 2014, 10, 18232-28237. [CrossRef]

44. Xie, Y.; Wang, T.-T.; Liu, X.-H.; Zou, K.; Deng, W.-Q. Capture and conversion of $\mathrm{CO}_{2}$ at ambient conditions by a conjugated microporous polymer. Nat. Commun. 2013, 4, 1960-1967. [CrossRef] [PubMed]

45. Zhou, L.; Li, N.; Owens, G.; Chen, Z. Simultaneous removal of mixed contaminants, copper and norfloxacin, from aqueous solution by ZIF-8. Chem. Eng. J. 2019, 362, 628-637. [CrossRef]

46. Yao, J.; He, M.; Wang, K.; Chen, R.; Zhong, Z.; Wang, H. High-yield synthesis of zeolitic imidazolate frameworks from stoichiometric metal and ligand precursor aqueous solutions at room temperature. CrystEngComm 2013, 15, 3601-3606. [CrossRef]

47. Giraldo, L.; Barranco, M.B.; Húmpola, P.; Carlos, J.; Piraján, M. the adsorption of phenols derivatives in aqueous solution. J. Chem. 2017, 8, 6940-6949.

48. Song, Q.; Nataraj, S.K.; Roussenova, M.V.; Tan, J.C.; Hughes, D.J.; Li, W.; Bourgoin, P.; Alam, M.A.; Cheetham, A.K.; Al-Muhtaseb, S.A.; et al. Zeolitic imidazolate framework (ZIF-8) based polymer nanocomposite membranes for gas separation. Energy Environ. Sci. 2012, 5, 8359-8366. [CrossRef]

49. Luanwuthi, S.; Krittayavathananon, A.; Srimuk, P.; Sawangphruk, M. In situ synthesis of permselective zeolitic imidazolate framework-8/graphene oxide composites: Rotating disk electrode and Langmuir adsorption isotherm. RSC Adv. 2015, 5, 46617-46623. [CrossRef]

50. Mao, J.; Ge, M.; Huang, J.; Lai, Y.; Lin, C.; Zhang, K.; Meng, K.; Tang, Y. Constructing multifunctional MOF@rGO hydro-/aerogels by the self-assembly process for customized water remediation. J. Mater. Chem. A 2017, 5, 11873-11881. [CrossRef]

51. Biswal, B.P.; Shinde, D.B.; Pillai, V.K.; Banerjee, R. Stabilization of graphene quantum dots (GQDs) by encapsulation inside zeolitic imidazolate framework nanocrystals for photoluminescence tuning. Nanoscale 2013, 5, 10556-10561. [CrossRef]

52. Tanaka, S.; Fujita, K.; Miyake, Y.; Miyamoto, M.; Hasegawa, Y.; Makino, T.; Van Der Perre, S.; Cousin Saint Remi, J.; Van Assche, T.; Baron, G.V.; et al. Adsorption and Diffusion Phenomena in Crystal Size Engineered ZIF-8 MOF. J. Phys. Chem. C 2015, 119, 28430-28439. [CrossRef] 
53. Pham, T.T.; Le, L.N.; Nguyen, H.N.; Luong, T.T.K.; Pham, T.N.; Nguyen, H.L.; Nguyen, T.K. Encapsulating gold nanoparticles in zeolitic imidazolate framework crystal for novel optical response. Polyhedron 2018, 148, 171-177. [CrossRef]

54. Wang, S.; Ma, Z.; Du, X.; Zhang, S.; Chen, Z. Lanthanum doping of metal-organic frameworks-5 and its effect on thermal stability and $\mathrm{CO}_{2}$ adsorption property. Mater. Express 2018, 8, 381-387. [CrossRef]

55. Li, P.Z.; Wang, X.J.; Liu, J.; Lim, J.S.; Zou, R.; Zhao, Y. A Triazole-Containing Metal-Organic Framework as a Highly Effective and Substrate Size-Dependent Catalyst for $\mathrm{CO}_{2}$ Conversion. J. Am. Chem. Soc. 2016, 138, 2142-2145. [CrossRef] [PubMed]

56. Abhang, R.M.; Wani, K.S.; Patil, V.S. Synthesis and Characterization of ZIF-8 Filler for Preparation of Mixed Matrix Membrane. Int. J. Sci. Eng. Res. 2015, 6, 1276-1280.

57. Adeleye, A.I. Heterogeneous Catalytic Conversion of Carbon Dioxide to Value Added Chemicals. Ph.D. Thesis, London South Bank University, London, UK, June 2015.

58. Kim, H.U.; Babu, R.; Roshan, R.; Park, D.W. Catalytic performance of metal azolate frameworks in the solventless synthesis of cyclic carbonates from $\mathrm{CO}_{2}$ and epoxides. Appl. Catal. A Gen. 2017, 538, 59-65. [CrossRef]

59. Kim, J.; Kim, S.N.; Jang, H.G.; Seo, G.; Ahn, W.S. $\mathrm{CO}_{2}$ cycloaddition of styrene oxide over MOF catalysts. Appl. Catal. A Gen. 2013, 453, 175-180. [CrossRef]

60. Wang, M.; She, Y.; Zhou, X.; Ji, H. Efficient solvent-free synthesis of chloropropene carbonate from the coupling reaction of $\mathrm{CO}_{2}$ and epichlorohydrin catalyzed by magnesium porphyrins as chlorophyll-like catalysts. Chin. J. Chem. Eng. 2011, 19, 446-451. [CrossRef]

61. Onyenkeadi, V.; Aboelazayem, O.; Saha, B. Systematic multivariate optimisation of butylene carbonate synthesis via $\mathrm{CO}_{2}$ utilisation using graphene-inorganic nanocomposite catalysts. Catal. Today 2019, 3, 1-13. [CrossRef]

62. Saada, R.; Kellici, S.; Heil, T.; Morgan, D.; Saha, B. Greener synthesis of dimethyl carbonate using a novel ceria-zirconia oxide/graphene nanocomposite catalyst. Appl. Catal. B Environ. 2015, 168-169, 353-362. [CrossRef]

63. Liang, J.; Chen, R.-P.; Wang, X.-Y.; Liu, T.-T.; Wang, X.-S.; Huang, Y.-B.; Cao, R. Postsynthetic ionization of an imidazole-containing metal-organic framework for the cycloaddition of carbon dioxide and epoxides. Chem. Sci. 2017, 8, 1570-1575. [CrossRef] [PubMed]

64. Adeleye, A.I.; Patel, D.; Niyogi, D.; Saha, B. Efficient and greener synthesis of propylene carbonate from carbon dioxide and propylene oxide. Ind. Eng. Chem. Res. 2014, 53, 18647-18657. [CrossRef]

65. Sathe, A.A.; Nambiar, A.M.; Sturgis, N.; Rioux, M. Synthesis of cyclic organic carbonates via catalytic oxidative carboxylation of olefins in flow reactors. Catal. Sci. Technol. 2017, 7, 2-3. [CrossRef]

66. Dhakshinamoorthy, A.; Asiri, A.M.; Garcia, H. Metal-organic frameworks as heterogeneous catalysts in liquid phase reactions: Why are they so exceptional? Chim. Oggi-Chem. Today 2015, 33, 40-45.

67. Mousavi, B.; Chaemchuen, S.; Phatanasri, S.; Chen, C.; Zeng, C.; Ganguly, R.; Zhuiykov, S.; Verpoort, F. Selective cyclodimerization of epichlorohydrin to dioxane derivatives over MOFs. Arab. J. Chem. 2017, 10, 1878-1888. [CrossRef]

68. Maeda, C.; Miyazaki, Y.; Ema, T. Recent progress in catalytic conversions of carbon dioxide. Catal. Sci. Technol. 2014, 4, 1482-1489. [CrossRef]

69. Carreon, M.A. Metal organic frameworks as catalysts in the conversion of $\mathrm{CO}_{2}$ to cyclic carbonates. Indian J. Chem.-Sect. Inorg. Phys. Theor. Anal. Chem. 2012, 51, 1306-1314.

70. Miralda, C.M.; MacIas, E.E.; Zhu, M.; Ratnasamy, P.; Carreon, M.A. Zeolitic imidazole framework-8 catalysts in the conversion of $\mathrm{CO}_{2}$ to chloropropene carbonate. ACS Catal. 2012, 2, 180-183. [CrossRef]

71. De Caro, P.; Bandres, M.; Urrutigoïty, M.; Cecutti, C.; Thiebaud-Roux, S. Recent progress in synthesis of glycerol carbonate and evaluation of its plasticizing properties. Front. Chem. 2019, 7, 1-13. [CrossRef]

72. Yuan, S.; Zou, L.; Li, H.; Chen, Y.P.; Qin, J.; Zhang, Q.; Lu, W.; Hall, M.B.; Zhou, H.C. Flexible Zirconium Metal-Organic Frameworks as Bioinspired Switchable Catalysts. Angew. Chem. -Int. Ed. 2016, 55, 10776-10780. [CrossRef]

(C) 2020 by the authors. Licensee MDPI, Basel, Switzerland. This article is an open access article distributed under the terms and conditions of the Creative Commons Attribution (CC BY) license (http://creativecommons.org/licenses/by/4.0/). 